NISTIR 7450

\title{
Effect of CuO Nanoparticle Concentration on R134a/Lubricant Pool Boiling Heat Transfer with Extensive Analysis
}

Mark A. Kedzierski

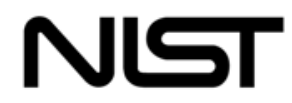

National Institute of Standards and Technology Technology Administration, U.S. Department of Commerce 
NISTIR 7450

\title{
Effect of CuO Nanoparticle Concentration on R134a/Lubricant Pool Boiling Heat Transfer with Extensive Analysis
}

\author{
Mark A. Kedzierski \\ U.S DEPARTMENT OF COMMERCE \\ National Institute of Standard and Technology \\ Building Environment Division \\ Building and Fire Research Laboratory \\ Gaithersburg, MD 20899-8631
}




\title{
Effect of CuO Nanoparticle Concentration on R134a/Lubricant Pool Boiling Heat Transfer with Extensive Analysis
}

\author{
M. A. Kedzierski \\ National Institute of Standards and Technology \\ Bldg. 226, Rm B114 \\ Gaithersburg, MD 20899 \\ Phone: (301) 975-5282 \\ Fax: (301) 975-8973
}

\begin{abstract}
This paper quantifies the influence of copper (II) oxide (CuO) nanoparticle concentration on the boiling performance of R134a/polyolester mixtures on a roughened, horizontal flat surface. Nanofluids are liquids that contain dispersed nano-size particles. Two lubricant based nanofluids (nanolubricants) were made with a synthetic polyolester and $30 \mathrm{~nm}$ diameter $\mathrm{CuO}$ particles to a $4 \%$ and a $2 \%$ volume fraction, respectively. As reported in a previous study for the $4 \%$ volume fraction nanolubricant, a $0.5 \%$ nanolubricant mass fraction with R134a resulted in a heat transfer enhancement relative to the heat transfer of pure R134a/polyolester (99.5/0.5) of between $50 \%$ and $275 \%$. The same study had shown that increasing the mass fraction of the $4 \%$ volume fraction nanolubricant resulted in smaller, but significant, boiling heat transfer enhancements. The present study shows that use of a nanolubricant with half the concentration of $\mathrm{CuO}$ nanoparticles ( $2 \%$ by volume) resulted in either no improvement or boiling heat transfer degradations with respect to the R134a/polyolester mixtures without nanoparticles. Consequently, significant refrigerant/lubricant boiling heat transfer enhancements are possible with nanoparticles; however, the nanoparticle concentration is an important determining factor. Further research with nanolubricants and refrigerants are required to establish a fundamental understanding of the mechanisms that control nanofluid heat transfer.
\end{abstract}

Keywords: additives, boiling, copper (II) oxide, enhanced heat transfer, nanotechnology, refrigerants, refrigerant/lubricant mixtures 


\section{TABLE OF CONTENTS}

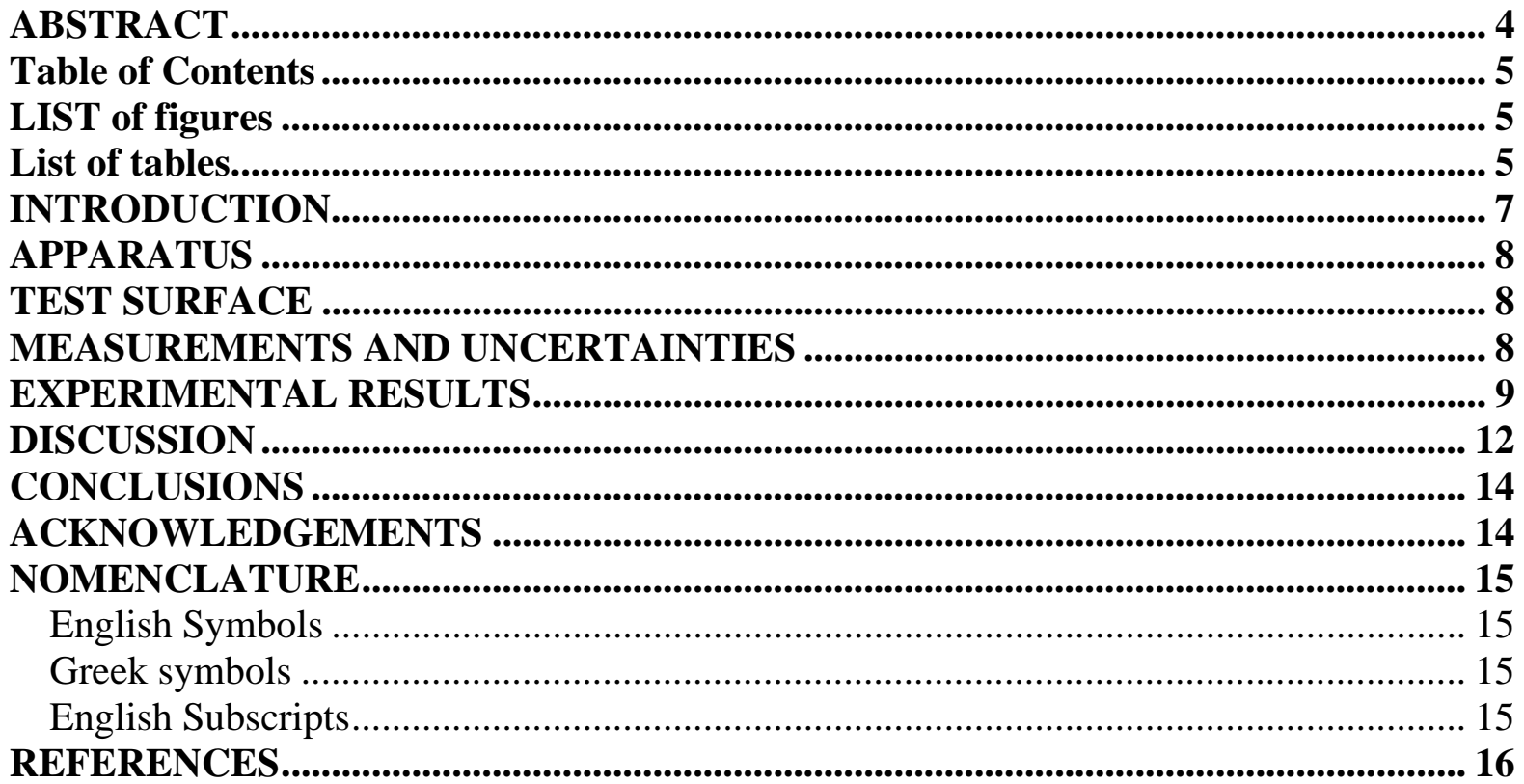

\section{LIST OF FIGURES}

Fig. 1 Schematic of test apparatus.

Fig. 2 OFHC copper flat test plate with cross-hatched surface and thermocouple coordinate system.......................................................................................................... 25

Fig. 3 R134a/RL68H with $2 \%$ volume $\mathrm{CuO}$ nanoparticle mixtures boiling curves for plain surface ............................................................................................................... 26

Fig. 4 R134a/RL68H with $4 \%$ volume $\mathrm{CuO}$ nanoparticle mixtures boiling curves for plain surface (Kedzierski and Gong, 2007) ................................................................ 27

Fig. 5 R134a/RL68H mixtures boiling curves for plain surface (Kedzierski and Gong, 2007)

Fig. 6 Heat flux of R134a/RL68H mixtures with $\mathrm{CuO}$ nanoparticles relative to that of R134a/RL68H mixtures without $\mathrm{CuO}$ nanoparticles for the 99.5/0.5 composition

Fig. 7 Heat flux of $\mathrm{R} 134 \mathrm{a} / \mathrm{RL} 68 \mathrm{H}$ mixtures with $\mathrm{CuO}$ nanoparticles relative to that of R134a/RL68H mixtures without $\mathrm{CuO}$ nanoparticles for the 99/1 composition .. 30

Fig. 8 Heat flux of R134a/RL68H mixtures with $\mathrm{CuO}$ nanoparticles relative to that of R134a/RL68H mixtures without $\mathrm{CuO}$ nanoparticles for the 98/2 composition .. 31

Fig. A.1 Expanded relative uncertainty in the heat flux of the surface at the $95 \%$ confidence level. 32

Fig. A.2 Expanded uncertainty in the temperature of the surface at the $95 \%$ confidence level.

\section{LIST OF TABLES}

Table 1 Conduction model choice. 


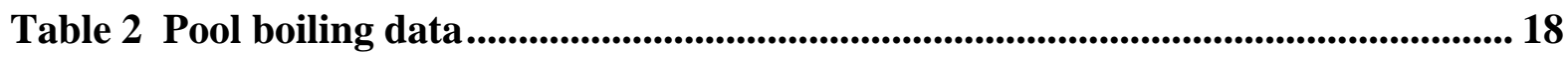

Table 3 Number of test days and data points ............................................................ 22

Table 4 Estimated parameters for cubic boiling curve fits for plain copper surface.... 22

Table 5 Residual standard deviation of $\Delta T_{\mathrm{s}}$......................................................................... 23

Table 6 Average magnitude of $95 \%$ multi-use confidence interval for mean $T_{w}-T_{s}(K)$

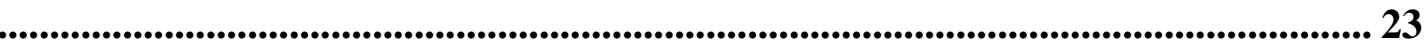




\section{INTRODUCTION}

In recent years, the U.S. National Nanotechnology Initiative (NNI) has, in large part, driven the deluge of heat transfer property investigations of liquids with dispersed nano-size particles called nanofluids. Much of the justification for nanofluids heat transfer research rests on the potential improvement in the thermal conductivity of the fluids due to nanoparticles. For example, Eastman et al. (2001) found that more than a $40 \%$ increase in the thermal conductivity of a liquid could be achieved by adding nanoparticles to a volume fraction of approximately $0.4 \%$. Most nanofluid boiling heat transfer studies have been conducted with water based nanofluids (Bang and Chang (2004), Wen and Ding (2005), and You et al. (2003)). Although, You et al. (2003) and Bang and Chang (2004) did not observe a pool-boiling enhancement with water-based nanofluids, Wen and Ding (2005) did.

Kedzierski and Gong (2007) also obtained a boiling heat transfer enhancement with nanofluids for refrigerant/lubricant mixtures by using a lubricant-based nanofluid (nanolubricant). The study obtained between $50 \%$ and $275 \%$ improvement in the boiling heat transfer with a nanolubricant where $4 \%$ of volume was occupied by $30 \mathrm{~nm}$ diameter $\mathrm{CuO}$ nanoparticles. Not much is presently known about how the material of the particles, their shape, size, distribution, and concentration affect refrigerant/lubricant boiling performance. Consequently, this study is a first step toward the understanding of how one of the aforementioned parameters influence heat transfer: nanoparticle concentration.

In order to investigate the influence of nanoparticle concentration on refrigerant/lubricant pool boiling, the boiling heat transfer of three R134a/nanolubricant mixtures on a roughened, horizontal flat (plain), copper surface was measured. A commercial polyolester lubricant $\left(\mathrm{RL}_{68 \mathrm{H}^{1}}\right)$ with a nominal kinematic viscosity of $72.3 \mu \mathrm{m}^{2} / \mathrm{s}$ at $313.15 \mathrm{~K}$ was the base lubricant that was mixed with nominally $30 \mathrm{~nm}$ diameter copper (II) oxide (CuO) nanoparticles. Copper (II) oxide (79.55 g/mol) has many commercial applications including use as an optical glasspolishing agent. A manufacturer used a proprietary surfactant at a mass between $5 \%$ and $15 \%$ of the mass of the $\mathrm{CuO}$ as a dispersant for the $\mathrm{RL} 68 \mathrm{H} / \mathrm{CuO}$ mixture (nanolubricant). The manufacturer made the mixture such that $40 \%$ of the volume was $\mathrm{CuO}$ particles. The mixture was diluted at NIST to a $2 \%$ volume fraction of CuO by adding neat RL68H and ultrasonically mixing the solution for approximately $24 \mathrm{~h}$. The particle size and dispersion were verified by a light scattering technique and were found to be approximately $35 \mathrm{~nm}$ and well dispersed with little particle agglomeration (Sung, 2006). The RL68H/CuO (98/2) ${ }^{2}$ volume fraction mixture, a.k.a. RL68H2Cu, was mixed with pure R134a to obtain three R134a/RL68H2Cu mixtures at nominally $0.5 \%, 1 \%$, and $2 \%$ mass fractions for the boiling tests. The present measurements were compared to measurements from Kedzierski and Gong (2007) that were obtained with an identical experimental method with the exception that the volume fraction of the nanolubricant was $4 \%(\mathrm{R} 134 \mathrm{a} / \mathrm{RL} 68 \mathrm{H} 4 \mathrm{Cu})$ rather than $2 \%$. In addition, the boiling heat transfer of three R134a/RL68H mixtures $(0.5 \%, 1 \%$, and $2 \%$

\footnotetext{
${ }^{1}$ Certain commercial equipment, instruments, or materials are identified in this paper in order to specify the experimental procedure adequately. Such identification is not intended to imply recommendation or endorsement by the National Institute of Standards and Technology, nor is it intended to imply that the materials or equipment identified are necessarily the best available for the purpose.

${ }^{2}$ The equivalent mixture is $\mathrm{RL} 68 \mathrm{H} / \mathrm{CuO}(95.6 / 4.4)$ in terms of mass.
} 
mass fractions), without nanoparticles, was obtained from the previous study to serve as a baseline for comparison.

\begin{abstract}
APPARATUS
Figure 1 shows a schematic of the apparatus that was used to measure the pool boiling data of this study. More specifically, the apparatus was used to measure the liquid saturation temperature $\left(T_{\mathrm{s}}\right)$, the average pool-boiling heat flux $\left(q^{\prime \prime}\right)$, and the wall temperature $\left(T_{\mathrm{w}}\right)$ of the test surface. The three principal components of the apparatus were the test chamber, the condenser, and the purger. The internal dimensions of the test chamber were $25.4 \mathrm{~mm} \times$ $257 \mathrm{~mm} \times 1.54 \mathrm{~m}$. The test chamber was charged with approximately $7 \mathrm{~kg}$ of refrigerant, giving a liquid height of approximately $80 \mathrm{~mm}$ above the test surface. As shown in Fig. 1, the test section was visible through two opposing, flat $150 \mathrm{~mm} \times 200 \mathrm{~mm}$ quartz windows. The bottom of the test surface was heated with high velocity $(2.5 \mathrm{~m} / \mathrm{s})$ water flow. The vapor produced by liquid boiling on the test surface was condensed by the brine-cooled, shell-andtube condenser and returned as liquid to the pool by gravity. Further details of the test apparatus can be found in Kedzierski (2002) and Kedzierski (2001).
\end{abstract}

\title{
TEST SURFACE
}

Figure 2 shows the oxygen-free high-conductivity (OFHC) copper flat test plate used in this study. The test plate was machined out of a single piece of OFHC copper by electric discharge machining (EDM). A tub grinder was used to finish the heat transfer surface of the test plate with a crosshatch pattern. Average roughness measurements were used to estimate the range of average cavity radii for the surface to be between $12 \mu \mathrm{m}$ and $35 \mu \mathrm{m}$. The relative standard uncertainty of the cavity measurements were approximately $\pm 12 \%$. Further information on the surface characterization can be found in Kedzierski (2001).

\section{MEASUREMENTS AND UNCERTAINTIES}

The standard uncertainty $\left(u_{i}\right)$ is the positive square root of the estimated variance $u_{i}{ }^{2}$. The individual standard uncertainties are combined to obtain the expanded uncertainty $(U)$, which is calculated from the law of propagation of uncertainty with a coverage factor. All measurement uncertainties are reported at the $95 \%$ confidence level except where specified otherwise. For the sake of brevity, only an outline of the basic measurements and uncertainties is given below. Complete detail on the heat transfer measurement techniques and uncertainties can be found in Kedzierski (2000) and Appendix A, respectively.

All of the copper-constantan thermocouples and the data acquisition system were calibrated against a glass-rod standard platinum resistance thermometer (SPRT) and a reference voltage to a residual standard deviation of $0.005 \mathrm{~K}$. Considering the fluctuations in the saturation temperature during the test and the standard uncertainties in the calibration, the expanded uncertainty of the average saturation temperature was no greater than $0.04 \mathrm{~K}$. Consequently, it is believed that the expanded uncertainty of the temperature measurements was less than $0.1 \mathrm{~K}$.

Twenty $0.5 \mathrm{~mm}$ diameter thermocouples were force fitted into the wells of the side of the test plate shown in Fig. 2. The heat flux and the wall temperature were obtained by regressing the measured temperature distribution of the block to the governing two-dimensional 
conduction equation (Laplace equation). In other words, rather than using the boundary conditions to solve for the interior temperatures, the interior temperatures were used to solve for the boundary conditions following a backward stepwise procedure given in Kedzierski $(1995)^{3}$. Fourier's law and the fitted constants from the Laplace equation were used to calculate the average heat flux $\left(q^{\prime \prime}\right)$ normal to and evaluated at the heat transfer surface based on its projected area. The average wall temperature $\left(T_{\mathrm{w}}\right)$ was calculated by integrating the local wall temperature $(T)$. The wall superheat was calculated from $T_{\mathrm{w}}$ and the measured temperature of the saturated liquid $\left(T_{\mathrm{s}}\right)$. Considering this, the relative expanded uncertainty in the heat flux $\left(U_{q^{\prime \prime}}\right)$ was greatest at the lowest heat fluxes, approaching $20 \%$ of the measurement near $10 \mathrm{~kW} / \mathrm{m}^{2}$. In general, the $U_{q^{\prime \prime}}$ remained approximately within $6 \%$ for heat fluxes greater than $40 \mathrm{~kW} / \mathrm{m}^{2}$. The average random error in the wall superheat $\left(U_{\mathrm{Tw}}\right)$ was between $0.05 \mathrm{~K}$ and $0.2 \mathrm{~K}$. Plots of $U_{q^{\prime \prime}}$ and $U_{\mathrm{Tw}}$ versus heat flux can be found in Appendix A.

\section{EXPERIMENTAL RESULTS}

The heat flux was varied approximately between $10 \mathrm{~kW} / \mathrm{m}^{2}$ and $120 \mathrm{~kW} / \mathrm{m}^{2}$ to simulate a range of possible operating conditions for R134a chillers. All pool-boiling tests were taken at 277.6 K saturated conditions. The data were recorded consecutively starting at the largest heat flux and descending in intervals of approximately $4 \mathrm{~kW} / \mathrm{m}^{2}$. The descending heat flux procedure minimized the possibility of any hysteresis effects on the data, which would have made the data sensitive to the initial operating conditions. Table 2 presents the measured heat flux and wall superheat for all the data of this study. Table 3 gives the number of test days and data points for each fluid.

The mixtures were prepared by charging the test chamber (see Fig. 1) with pure R134a to a known mass. Next, a measured mass of nanolubricant or lubricant was injected with a syringe through a port in the test chamber. The refrigerant/lubricant solution was mixed by flushing pure refrigerant through the same port where the lubricant was injected. All compositions were determined from the masses of the charged components and are given on a mass fraction basis. The maximum uncertainty of the composition measurement is approximately $0.02 \%$, e.g., the range of a $2.0 \%$ composition is between $1.98 \%$ and $2.02 \%$. Nominal or target mass compositions are used in the discussion. For example, the "actual" mass composition of the RL68H2Cu in the R134a/ RL68H2Cu (99.5/0.5) mixture was $0.51 \% \pm 0.02 \%$. Likewise, the RL68H2Cu mass fractions for R134a/ RL68H2Cu (99/1) and the R134a/ RL68H2Cu (98/2) mixtures were $0.99 \% \pm 0.02 \%$ and $2.00 \% \pm 0.02 \%$, respectively.

The effect of mass fraction on R134a/RL68H2Cu pool boiling for the $2 \%$ volume fraction nanolubricant (RL68H2Cu) is shown in Fig. 3. Figure 3 is a plot of the measured heat flux $(q ")$ versus the measured wall superheat $\left(T_{\mathrm{w}}-T_{\mathrm{s}}\right)$ for the R134a/RL68H2Cu mixtures at a saturation temperature of $277.6 \mathrm{~K}$. The solid lines shown in Fig. 3 are cubic best-fit regressions or estimated means of the data. Five of the 243 measurements were removed before fitting because they were identified as "outliers" based on having both high influence and high-leverage (Belsley et al., 1980). Table 4 gives the constants for the cubic regression

\footnotetext{
${ }^{3}$ For the record, Table 1 provides functional forms of the Laplace equation that were used in this study in the same way as was done in Kedzierski (1995) and in similar studies by this author.
} 
of the superheat versus the heat flux for all of the fluids tested here. The residual standard deviation of the regressions - representing the proximity of the data to the mean - are given in Table 5. The dashed lines to either side of the mean represent the lower and upper $95 \%$ simultaneous (multiple-use) confidence intervals for the mean. From the confidence intervals, the expanded uncertainty of the estimated mean wall superheat was on average approximately $0.27 \mathrm{~K}$. Table 6 provides the average magnitude of $95 \%$ multi-use confidence interval for the fitted wall superheat for all of the test data.

Figure 3 shows that the means of the R134a/RL68H2Cu (99/1) and the R134a/RL68H2Cu (98/2) superheat measurements are within approximately $1 \mathrm{~K}$ for the entire heat flux range that was tested. For heat fluxes less than approximately $75 \mathrm{~kW} / \mathrm{m}^{2}$, the R134a/RL68H2Cu (99/1) mixture mean superheat is less than that of the R134a/RL68H2Cu (98/2) mixture. For heat fluxes larger than $75 \mathrm{~kW} / \mathrm{m}^{2}$, the R134a/RL68H2Cu (98/2) mixture exhibits the unusual characteristic of having an enhanced boiling performance as compared to the R134a/RL68H2Cu (99/1) mixture. However, the confidence intervals coincide for heat fluxes larger than $75 \mathrm{~kW} / \mathrm{m}^{2}$ indicating that no difference can be discerned between the two data sets. For most heat fluxes, the R134a/RL68H2Cu (99.5/0.5) superheat measurements, represented by the closed triangles, are as much as $4 \mathrm{~K}$ less than those of the 99/1 and the 98/2 mixtures. For comparison, the mean of the pure R134a boiling curve taken from Kedzierski and Gong (2007) is provided as a coarsely dashed line.

The effect of the $4 \%$ volume fraction nanolubricant (RL68H4Cu) mass fraction on R134a/ RL68H4Cu pool boiling is shown in Fig. 4. Figure 4 is a plot of the measured heat flux ( $q$ ") versus the measured wall superheat $\left(T_{\mathrm{w}}-T_{\mathrm{s}}\right)$ for the R134a/RL68H4Cu mixtures at a saturation temperature of $277.6 \mathrm{~K}$ taken from Kedzierski and Gong (2007). The means of the R134a/RL68H4Cu (99/1) and the R134a/RL68H4Cu (98/2) superheat measurements are within approximately $1 \mathrm{~K}$ for the entire heat flux range that was tested. For heat fluxes less than approximately $30 \mathrm{~kW} / \mathrm{m}^{2}$, and greater than approximately $60 \mathrm{~kW} / \mathrm{m}^{2}$, the $\mathrm{R} 134 \mathrm{a} / \mathrm{RL} 68 \mathrm{H} 4 \mathrm{Cu}(99 / 1)$ mixture mean superheat is less than that of the R134a/RL68H4Cu (98/2) mixture. For heat fluxes between these limits, the R134a/RL68H4Cu (98/2) mixture exhibits the unusual characteristic of having an enhanced boiling performance as compared to the R134a/RL68H4Cu (99/1) mixture. For most heat fluxes, the R134a/RL68H4Cu $(99.5 / 0.5)$ superheat measurements, represented by the open triangles, are significantly less that those of the 99/1 and the 98/2 mixtures. The average expanded uncertainty of the estimated mean wall superheat for the three refrigerant/nanolubricant mixtures was $0.23 \mathrm{~K}$.

Figure 5 is a plot of the measured heat flux ( $q$ ") versus the measured wall superheat $\left(T_{\mathrm{w}}-T_{\mathrm{s}}\right)$ for three R134a/RL68H mixtures at a saturation temperature of $277.6 \mathrm{~K}$ taken from Kedzierski and Gong (2007). Figure 5 illustrates the effect of the pure lubricant mass fraction on R134a/lubricant pool boiling. Comparison of the three mean boiling curves shows that the superheats are within approximately $1 \mathrm{~K}$ of each other for heat fluxes between approximately $30 \mathrm{~kW} / \mathrm{m}^{2}$ and $90 \mathrm{~kW} / \mathrm{m}^{2}$. For the same heat flux range, the superheat for the pure R134a is roughly $3 \mathrm{~K}$ less than that for the mixtures translating into a heat transfer degradation with respect to R134a. 
A more precise examination of the effect of $\mathrm{CuO}$ nanoparticle concentration on boiling performance, for a given R134a/nanolubricant mass fraction, is given in Figs. 6 through 8. Each figure compares the relative performance of the R134a/RL68H4Cu and the $\mathrm{R} 134 \mathrm{a} / \mathrm{RL} 68 \mathrm{H} 2 \mathrm{Cu}$ for one of the target mass fractions. A heat transfer enhancement exists where the heat flux ratio is greater than one and the $95 \%$ simultaneous confidence intervals (depicted by the shaded regions) do not include the value one.

Figure 6 plots the ratio of the R134a/RL68H2Cu heat flux to the R134a/RL68H heat flux ( $q$ " ${ }_{\mathrm{np}} / q^{\prime}{ }_{\mathrm{PL}}$ ) versus the R134a/RL68H2Cu mixture heat flux ( $\left.q{ }^{\prime} \mathrm{CuO}\right)$ at the same wall superheat for the 99.5/0.5 mixture composition. The heat flux ratio varies between roughly 0.73 and 1.12 for the R134a/RL68H2Cu (99.5/0.5) mixture for heat fluxes between $7 \mathrm{~kW} / \mathrm{m}^{2}$ and $93 \mathrm{~kW} / \mathrm{m}^{2}$. The R134a/RL68H2Cu (99.5/0.5) mixture shows a maximum heat flux ratio of approximately 1.12; however, the maximum resides in a region between $50 \mathrm{~kW} / \mathrm{m}^{2}$ and $93 \mathrm{~kW} / \mathrm{m}^{2}$ where no difference can be established between the two fluids because the confidence intervals include the value of one. Overall, the average heat flux ratio for the R134a/RL68H2Cu (99.5/0.5) mixture from approximately $7 \mathrm{~kW} / \mathrm{m}^{2}$ to $93 \mathrm{~kW} / \mathrm{m}^{2}$ was 0.91 . In contrast, Fig. 6 shows that a significant boiling heat transfer enhancement over that of the R134a/RL68H (99.5/0.5) mixture without nanoparticles is obtained when the nanoparticle volume faction of the lubricant is increased from $2 \%$ to $4 \%$. More specifically, the heat flux ratio for the $\mathrm{R} 134 \mathrm{a} / \mathrm{RL} 68 \mathrm{H} 4 \mathrm{Cu}(99.5 / 0.5)$ mixture varies between roughly 1.5 and 3.75 for heat fluxes between $10 \mathrm{~kW} / \mathrm{m}^{2}$ and $110 \mathrm{~kW} / \mathrm{m}^{2}$. Overall, the average heat flux ratio for the R134a/RL68H4Cu (99.5/0.5) mixture from approximately $8 \mathrm{~kW} / \mathrm{m}^{2}$ to $94 \mathrm{~kW} / \mathrm{m}^{2}$ was 2.15 . Consequently, the average heat flux ratio for the $4 \% \mathrm{CuO}$ volume fraction mixture was nearly 2.4 times larger than that for the $2 \% \mathrm{CuO}$ volume fraction mixture for approximately the same heat flux range.

Figure 7 plots the ratio of the R134a/RL68H2Cu heat flux to the R134a/RL68H heat flux $\left(q{ }^{\prime \prime} / q^{\prime}{ }_{\mathrm{PL}}\right)$ versus the R134a/RL68H mixture heat flux $\left(q{ }^{\prime}{ }_{\mathrm{PL}}\right)$ at the same wall superheat for the 99/1 mixture. The heat flux ratio varies between roughly 0.78 and 0.33 for the R134a/RL68H2Cu (99/1) mixture for heat fluxes between $9 \mathrm{~kW} / \mathrm{m}^{2}$ and $93 \mathrm{~kW} / \mathrm{m}^{2}$. The R134a/RL68H2Cu (99/1) mixture shows a maximum heat flux ratio of approximately 0.78 at a heat flux of approximately $9 \mathrm{~kW} / \mathrm{m}^{2}$. Overall, the average heat flux ratio for the R134a/RL68H2Cu (99/1) mixture from approximately $9 \mathrm{~kW} / \mathrm{m}^{2}$ to $93 \mathrm{~kW} / \mathrm{m}^{2}$ was 0.44 . In contrast, Fig. 7 shows that a significant boiling heat transfer enhancement over that of the R134a/RL68H (99/1) mixture without nanoparticles is obtained when the nanoparticle volume faction of the lubricant is increased from $2 \%$ to $4 \%$. More specifically, the heat flux ratio for the $\mathrm{R} 134 \mathrm{a} / \mathrm{RL} 68 \mathrm{H} 4 \mathrm{Cu}(99 / 1)$ mixture varies between roughly 1.54 and 1.05 for heat fluxes between $5 \mathrm{~kW} / \mathrm{m}^{2}$ and $85 \mathrm{~kW} / \mathrm{m}^{2}$. Overall, the average heat flux ratio for the R134a/RL68H4Cu (99/1) mixture from approximately $5 \mathrm{~kW} / \mathrm{m}^{2}$ to $85 \mathrm{~kW} / \mathrm{m}^{2}$ was 1.19 . For a shared heat flux range between $9 \mathrm{~kW} / \mathrm{m}^{2}$ and $85 \mathrm{~kW} / \mathrm{m}^{2}$, the average heat flux ratio for the $4 \% \mathrm{CuO}$ volume fraction mixture was approximately 2.6 times larger than that for the $2 \%$ $\mathrm{CuO}$ volume fraction mixture.

Figure 8 plots the ratio of the R134a/RL68H2Cu heat flux to the R134a/RL68H heat flux $\left(q{ }^{\prime n p} / q^{\prime \prime}\right.$ ) versus the R134a/RL68H mixture heat flux $\left(q "{ }_{\mathrm{PL}}\right)$ at the same wall superheat for the 98/2 mixture. The heat flux ratio varies between roughly 0.88 and 0.33 for the 
R134a/RL68H2Cu (98/2) mixture for heat fluxes between $9 \mathrm{~kW} / \mathrm{m}^{2}$ and $76 \mathrm{~kW} / \mathrm{m}^{2}$. The $\mathrm{R} 134 \mathrm{a} / \mathrm{RL} 68 \mathrm{H} 2 \mathrm{Cu}(98 / 2)$ mixture shows a maximum heat flux ratio of approximately 0.88 at a heat flux of approximately $13 \mathrm{~kW} / \mathrm{m}^{2}$. Overall, the average heat flux ratio for the R134a/RL68H2Cu (98/2) mixture from approximately $9 \mathrm{~kW} / \mathrm{m}^{2}$ to $76 \mathrm{~kW} / \mathrm{m}^{2}$ was 0.51 . In contrast, Fig. 8 shows that when the nanoparticle volume faction of the lubricant is increased from $2 \%$ to $4 \%$ a boiling heat transfer enhancement over that of the R134a/RL68H (98/2) mixture is obtained for heat fluxes less than approximately $60 \mathrm{~kW} / \mathrm{m}^{2}$. More specifically, the heat flux ratio for the R134a/RL68H4Cu (98/2) mixture varies between roughly 1.53 and 0.70 for heat fluxes between $7 \mathrm{~kW} / \mathrm{m}^{2}$ and $100 \mathrm{~kW} / \mathrm{m}^{2}$. Overall, the average heat flux ratio for the R134a/RL68H4Cu (98/2) mixture from approximately $9 \mathrm{~kW} / \mathrm{m}^{2}$ to $76 \mathrm{~kW} / \mathrm{m}^{2}$ was 1.17. As a result, the average heat flux ratio for the $4 \% \mathrm{CuO}$ volume fraction mixture was nearly 2.3 times larger than that for the $2 \% \mathrm{CuO}$ volume fraction mixture for approximately the same heat flux range.

\section{DISCUSSION}

The heat transfer results summarized in Figs. 6 through 8 show that use of the $2 \% \mathrm{CuO}$ volume fraction nanolubricant with R134a results in a significantly smaller pool boiling heat flux than that exhibited with R134a and the nanolubricant with the $4 \% \mathrm{CuO}$ volume fraction. Overall, mixtures with the $4 \%$ volume fraction nanolubricant had boiling heat fluxes (for a given superheat) that were on average $140 \%$ larger than those for mixtures with the $2 \%$ $\mathrm{CuO}$ volume fraction nanolubricant. In fact, for most heat fluxes, the $2 \% \mathrm{CuO}$ volume fraction nanolubricant caused a heat transfer degradation with respect to the R134a/POE boiling performance, while the $4 \% \mathrm{CuO}$ volume fraction nanolubricant caused an enhancement relative to R134a/POE. Kedzierski and Gong (2007) have shown that improvement in nanolubricant thermal conductivity appears to be of secondary importance in its influence on boiling enhancement. Of primary importance in the enhancement of refrigerant/lubricant boiling appears to be the interaction of nanoparticles with bubbles. The fact that nanoparticles at a $2 \%$ volume fraction in the lubricant did not provide a boiling heat transfer enhancement while a $4 \%$ volume fraction did, may suggest a critical nanoparticle volume fraction that is necessary for boiling enhancement. It may be necessary for a nanoparticle volume fraction threshold to be exceeded before there is a sufficient number of nanoparticles to influence bubble growth and formation. A similar synergistic behavior of nanofluids was also seen by Prasher (2006) in his examination of a maximum enhancement of nanofluid thermal conductivity being achieved if there were sufficient nanoparticles to give an agglomeration rate of approximately $35 \%$.

The critical volume fraction of nanoparticles depends on the distribution of the nanoparticles among the excess layer, the surface, and the bulk of the boiling refrigerant/nanolubricant mixture. For this reason, it is speculated that a boiling enhancement or a boiling degradation is realized based on the coupling of the following three heat transfer mechanisms: (1) boiling enhancement via nanoparticle interaction with bubbles, (2) improved thermal conductivity of the lubricant excess layer by the accumulation of highly conductive nanoparticles, and (3) loss of nano-size nucleation sites due to nanoparticle filling of cavities. The last mechanism, the loss of nano-size sites, induces a loss in boiling performance. The surface cavities become saturated with nanoparticles leaving the remaining particles not trapped by the surface to be available for use in the first and second mechanisms. Some volume fraction 
greater than what is necessary to attain the saturated surface state is believed to be the critical or threshold nanoparticle volume fraction for achieving a boiling enhancement. The second mechanism, improved thermal conductivity of the excess layer, may improve boiling or even degrade it by the loss of wall superheat due to improved conduction from the surface. The first mechanism, the nanoparticle interaction with bubbles, is believed to be the primary contributor to improved boiling.

The above discussion brings to light the likelihood that filling of the cavities of the surface caused the boiling heat transfer degradation measured for the R134a/RL68H2Cu mixtures of this study. Das et al. (2003) have conjectured that the boiling heat transfer degradation that they measured for a water-based nanofluid was caused by nanoparticles plugging the surface, which caused a decrease in nucleation sites. Their conclusion was drawn from an analogy with water deposits that are typically found on surfaces used for boiling water. In order for a smoothing of the surface to decrease boiling, it must reduce the number of active boiling sites.

Following the critical radius criterion given by Carey (1992), the calculated range of active cavity radii for saturated R134a boiling at the present test conditions is between $50 \mu \mathrm{m}$ and $0.1 \mu \mathrm{m}$. The $R_{\mathrm{a}}$ roughness of the new, clean test surface before its use was $3.39 \mu \mathrm{m}$ as measured by the NIST Precision Engineering Division (Kedzierski, 2002). In addition, $R_{\mathrm{a}}$ roughness measurements were also made after boiling tests with a portable contacting stylus device while the boiling surface was in the test apparatus. The average $R_{\mathrm{a}}$ roughness of the surface after boiling the (98/2) RL68H4Cu mixture, with the test fluid removed from the apparatus, and while the nanolubricant excess layer was still on the surface, was approximately $2.9 \mu \mathrm{m}$. The average $R_{\mathrm{a}}$ roughness of the surface after it was then cleaned with acetone was approximately $3.0 \mu \mathrm{m}$. A statistical comparison supported the conclusion that no difference between the clean and the dirty roughness values could be claimed. In addition, given that the original roughness measurement and the measurements made on the installed test surface were done with different instruments, there would be little or no justification for claiming that $R_{\mathrm{a}}$ roughness has changed as far as the resolution and methodology of these instruments are concerned. Consequently, it is speculated that the nanoparticles smoothed the surface on the nano-scale without changing the gross roughness characteristics because the cavities are an order of magnitude larger than the nanoparticles. This suggests that cavities smaller than those predicted by the critical radius criterion for R134a are active sites for boiling R134a/lubricant mixtures.

Future research is required to investigate the influence of the particle material, its shape, size, distribution, and concentration on refrigerant boiling performance. Not only should the bulk concentration be studied, the distribution of the concentration of the nanoparticles within a particular system should be investigated along with the influence of nanoparticles on boiling surface roughness. Further investigation into the above effects may lead to a theory that can be used to develop nanolubricants that improve boiling heat transfer for the benefit of the refrigeration and air-conditioning industry. 


\section{CONCLUSIONS}

The influence of $\mathrm{CuO}$ nanoparticle concentration on the boiling performance of $\mathrm{R} 134 \mathrm{a} /$ polyolester mixtures on a roughened, horizontal flat surface was investigated. The measurements show that use of the $2 \% \mathrm{CuO}$ volume fraction nanolubricant with $\mathrm{R} 134 \mathrm{a}$ results in a significantly smaller pool boiling heat flux than that exhibited with R134a and the nanolubricant with the $4 \% \mathrm{CuO}$ volume fraction. Overall, mixtures with the $4 \%$ volume fraction nanolubricant had boiling heat fluxes (for a given superheat) that were on average $140 \%$ larger than those for mixtures with the $2 \%$ volume fraction nanolubricant. It was speculated that the $4 \% \mathrm{CuO}$ volume fraction was greater than some threshold $\mathrm{CuO}$ volume fraction resulting in sufficiently more nanoparticles for interaction with bubbles, thus resulting in a significant boiling heat tranfer enhancement as compared to boiling without nanoparticles. Conversely, the $2 \% \mathrm{CuO}$ volume fraction apparently was less than the required threshold $\mathrm{CuO}$ volume fraction, which resulted in reduced active boiling sites causing a corresponding degradation in the boiling heat transfer as compared to boiling without nanoparticles. For example, the average heat flux ratio for the R134a/RL68H2Cu (99.5/0.5), the R134a/RL68H2Cu (99/1), and the R134a/RL68H2Cu (98/2) mixtures from approximately $10 \mathrm{~kW} / \mathrm{m}^{2}$ to $90 \mathrm{~kW} / \mathrm{m}^{2}$ was $0.91,0.44$, and 0.51 , respectively.

It was speculated that enhancement or a boiling degradation is realized based on the coupling of the following three heat transfer mechanisms: (1) boiling enhancement via nanoparticle interaction with bubbles, (2) improved thermal conductivity of lubricant excess layer by the accumulation of highly conductive nanoparticles, and (3) loss of nanosize nucleation sites due to nanoparticle filling of cavities. The total number of nanoparticles in the test fluid are split between those within the nano-size cavities of the surface, those in the lubricant excess layer, those on the adiabatic surfaces, and those in the bulk liquid. Nanoparticles not trapped on the surfaces are available to interact with bubbles and posssibly induce a boiling enhancement. An overall improvement in the boiling heat transfer will result if the enhancement due to nanoparticle interactions more than compensates for the boiling heat transfer degradation as caused by the filling of boiling cavities with nanoparticles.

\section{ACKNOWLEDGEMENTS}

This work was funded by NIST. Thanks go to the following NIST personnel for their constructive criticism of the first draft of the manuscript: Dr. S. Treado, and Dr. P. Domanski. Thanks go to Mr. N. Sawant of the Catholic University of America for his constructive criticism of the second draft of the manuscript. Furthermore, the author extends appreciation to W. Guthrie and Mr. A. Heckert of the NIST Statistical Engineering Division for their consultations on the uncertainty analysis. Boiling heat transfer measurements were taken by Mr. David Wilmering of KT Consultants. The RL68H (EMKARATE RL 68H) was donated by Dr. S. Randles of Uniqema. The RL68H2Cu was manufactured by Nanophase Technologies with a copper (II) oxide and dispersant in RL68H especially for NIST. 


\section{NOMENCLATURE}

English Symbols

$A_{\mathrm{n}} \quad$ regression constant in Table $4 \mathrm{n}=0,1,2,3$

$L_{\mathrm{y}} \quad$ length of test surface (Fig. 2), $\mathrm{m}$

$q^{\prime \prime} \quad$ average wall heat flux, $\mathrm{W} \mathrm{m} \mathrm{m}^{-2}$

$T$ temperature, $\mathrm{K}$

$T_{\mathrm{w}} \quad$ temperature at roughened surface, $\mathrm{K}$

$U$ expanded uncertainty

$u_{\mathrm{i}} \quad$ standard uncertainty

$X \quad$ model terms given in Table 2

Greek symbols

$\Delta T_{\mathrm{s}} \quad$ wall superheat: $T_{\mathrm{w}}-T_{\mathrm{s}}, \mathrm{K}$

English Subscripts

CuO R134a/RL68H2Cu or R134a/RL68H4Cu mixture

L nanolubricant

PL R134a/RL68H mixture

q" heat flux

s saturated state

Tw wall temperature

w wall, heat transfer surface 


\section{REFERENCES}

Bang, I. C. and, Chang, S. H., 2004, "Boiling Heat Transfer Performance and Phenomena of $\mathrm{Al}_{2} \mathrm{O}_{3}$-Water Nanofluids From a Plain Surface in a Pool," Proceedings of ICAPP, Pittsburgh, PA, pp. 1437-1443.

Belsley, D. A., Kuh, E., and Welsch, R. E., 1980, Regression Diagnostics: Identifying Influential Data and Sources of Collinearity, New York: Wiley.

Carey, V. P., 1992, Liquid-Vapor Phase-Change Phenomena, Hemisphere, NY, pp. 186 191.

Das S. K., Putra, N. and Roetzel, W., 2003, "Pool Boiling of Nano-Fluids on Horizontal Narrow Tubes,” Int. J. Multiphase Flow, Vol. 29, pp. 1237-1247.

Eastman, J. A, Choi, S. U. S., Li, S., Yu, W., and Thompson, L. J., 2001, “Anomalously Increased Effective Thermal Conductivities of Ethylene Glycol-Based Nanofluids Containing Copper Nanoparticles,” Appl. Phys. Lett. 78, p.718-720.

Kedzierski, M. A, and Gong, M., 2007, "Effect of CuO Nanolubricant on R134a Pool Boiling Heat Transfer with Extensive Measurement and Analysis Details,” NISTIR 7454, U.S. Department of Commerce, Washington, D.C.

Kedzierski, M. A., 2002, "Use of Fluorescence to Measure the Lubricant Excess Surface Density During Pool Boiling,” Int. J. Refrigeration, Vol. 25, pp.1110-1122.

Kedzierski, M. A., 2001, "Use of Fluorescence to Measure the Lubricant Excess Surface Density During Pool Boiling,” NISTIR 6727, U.S. Department of Commerce, Washington, D.C.

Kedzierski, M. A., 2000, "Enhancement of R123 Pool Boiling by the Addition of Hydrocarbons,” Int. J. Refrigeration, Vol. 23, pp. 89-100.

Kedzierski, M. A., 1995, "Calorimetric and Visual Measurements of R123 Pool Boiling on Four Enhanced Surfaces,” NISTIR 5732, U.S. Department of Commerce, Washington, D.C.

Prasher, R., 2006, "Effect of Colloidal Chemistry on the Thermal Conductivity of Nanofluids,” Proceedings of ASME IMECE, IMECE2006-13142.

Sung, L., 2006, Private Communications, National Institute of Standards and Technology, Building and Fire Research Laboratory, Gaithersburg, MD.

Wen, D, and Ding, Y., 2005, "Experimental Investigation into the Pool Boiling Heat Transfer of Aqueous Based $\gamma$-Alumina Nanofluids,” J. of Nanoparticle Research, Vol. 7, pp. 265-274.

You, S. M., Kim, J. H., and Kim, K. H., 2003, "Effect of Nanoparticles on Critical Heat Flux of Water in Pool Boiling Heat Transfer,” Applied Physics Letter, 83 (16) pp. 375-377 
Table 1 Conduction model choice

\begin{tabular}{|c|c|}
\hline $\begin{array}{l}\mathrm{X}_{0}=\text { constant (all models) } \\
\qquad \mathrm{X}_{5}=\mathrm{y}\left(3 \mathrm{x}^{2}-\mathrm{y}^{2}\right) \quad \mathrm{X}_{6}=\end{array}$ & $\begin{array}{l}X_{1}=x \quad X_{2}=y \quad X_{3}=x y \\
4=x^{2}-y^{2} \\
\left(3 y^{2}-x^{2}\right) \quad X_{7}=x^{4}+y^{4}-6\left(x^{2}\right) y^{2} \\
=y x^{3}-x^{3}\end{array}$ \\
\hline $\begin{array}{l}\text { R134a/RL68H2Cu } \\
(99.5 / 0.5) \\
\text { (file: RL2Cu5.dat) } \\
\end{array}$ & $\begin{array}{c}\mathrm{X}_{1}, \mathrm{X}_{2}, \mathrm{X}_{4}, \mathrm{X}_{6}(95 \text { of } 243) 39 \% \\
\mathrm{X}_{1}, \mathrm{X}_{2}, \mathrm{X}_{4}(81 \text { of } 243) 33 \% \\
\mathrm{X}_{1}, \mathrm{X}_{2}(40 \text { of } 243) 17 \% \\
\end{array}$ \\
\hline $\begin{array}{l}\text { R134a/RL68H2Cu (99/1) } \\
\text { (file: RL2Cu1.dat) }\end{array}$ & $\begin{array}{c}\mathrm{X}_{1}, \mathrm{X}_{2}, \mathrm{X}_{4}, \mathrm{X}_{6}(113 \text { of } 291) 39 \% \\
\mathrm{X}_{1}, \mathrm{X}_{2}(27 \text { of } 291) 9 \% \\
\mathrm{X}_{1}, \mathrm{X}_{2}, \mathrm{X}_{4}(25 \text { of } 291) 8 \% \\
\mathrm{X}_{1}, \mathrm{X}_{2}, \mathrm{X}_{4}, \mathrm{X}_{6}, \mathrm{X}_{7}(25 \text { of } 291) 8 \%\end{array}$ \\
\hline $\begin{array}{l}\text { R134a/RL68H2Cu (98/2) } \\
\text { (file: RL2Cu2.dat) }\end{array}$ & $\begin{array}{c}\mathrm{X}_{1}, \mathrm{X}_{2}, \mathrm{X}_{3}, \mathrm{X}_{4}, \mathrm{X}_{6}(61 \text { of } 208) 29 \% \\
\mathrm{X}_{1}, \mathrm{X}_{2}, \mathrm{X}_{3}, \mathrm{X}_{4}(49 \text { of } 208) 23 \% \\
\mathrm{X}_{1}, \mathrm{X}_{2}, \mathrm{X}_{3}, \mathrm{X}_{4}, \mathrm{X}_{5}, \mathrm{X}_{6}(20 \text { of } 208) 9 \% \\
\mathrm{X}_{1}, \mathrm{X}_{2}(18 \text { of } 208) 8 \%\end{array}$ \\
\hline
\end{tabular}


Table 2 Pool boiling data

R134a/RL68H2Cu (99.5/0.5) File: RL2Cu5.dat

\begin{tabular}{|c|c|}
\hline $\begin{array}{l}\Delta T_{\mathrm{s}} \\
(\mathrm{K})\end{array}$ & $\begin{array}{c}q^{\prime \prime} \\
\left(\mathrm{W} / \mathrm{m}^{2}\right)\end{array}$ \\
\hline 12.09 & 116062. \\
\hline 12.14 & 116834. \\
\hline 12.04 & 118800. \\
\hline 11.56 & 107105. \\
\hline 11.51 & 107384. \\
\hline 11.46 & 106020. \\
\hline 11.46 & 106020. \\
\hline 11.11 & 97450. \\
\hline 11.14 & 95819. \\
\hline 10.79 & 85973. \\
\hline 10.82 & 84869. \\
\hline 10.89 & 84455. \\
\hline 10.44 & 73303. \\
\hline 10.42 & 70473. \\
\hline 10.51 & 69348. \\
\hline 10.42 & 63799. \\
\hline 10.37 & 60320. \\
\hline 10.37 & 59423. \\
\hline 9.83 & 49768. \\
\hline 9.80 & 48415. \\
\hline 9.86 & 48287. \\
\hline 9.18 & 38654. \\
\hline 9.23 & 37767. \\
\hline 9.22 & 36896. \\
\hline 8.52 & 29555. \\
\hline 8.50 & 28838. \\
\hline 8.49 & 28478. \\
\hline 7.73 & 22185. \\
\hline 7.75 & 21891. \\
\hline 7.71 & 21621. \\
\hline 6.67 & 17071. \\
\hline 6.59 & 16619. \\
\hline 6.56 & 16418. \\
\hline 5.27 & 11078. \\
\hline 4.97 & 10280. \\
\hline 4.88 & 9990. \\
\hline 3.33 & 6456. \\
\hline 3.23 & 6391. \\
\hline 10.72 & 122172. \\
\hline 10.58 & 122510. \\
\hline 10.43 & 122798. \\
\hline 9.92 & 113828. \\
\hline 9.77 & 111100. \\
\hline 9.71 & 111160. \\
\hline 9.45 & 104688. \\
\hline 9.52 & 106670. \\
\hline 9.47 & 103176. \\
\hline 9.19 & 90667. \\
\hline 9.42 & 89231. \\
\hline 9.55 & 88706. \\
\hline 9.32 & 76039. \\
\hline 9.38 & 75007. \\
\hline 9.43 & 73995. \\
\hline 9.12 & 63872. \\
\hline 9.15 & 63185. \\
\hline
\end{tabular}

\begin{tabular}{|c|c|}
\hline 9.20 & 63089. \\
\hline 8.78 & 52947. \\
\hline 8.79 & 51234. \\
\hline 8.84 & 50086. \\
\hline 4.75 & 12813. \\
\hline 4.62 & 12461. \\
\hline 4.55 & 12027. \\
\hline 3.01 & 7217. \\
\hline 2.81 & 6715. \\
\hline 11.63 & 115191. \\
\hline 11.82 & 114396. \\
\hline 11.88 & 114094. \\
\hline 11.50 & 103751. \\
\hline 11.36 & 103616. \\
\hline 11.18 & 103820. \\
\hline 10.63 & 93622. \\
\hline 10.56 & 93378. \\
\hline 10.51 & 92885. \\
\hline 10.18 & 83975. \\
\hline 10.31 & 84252. \\
\hline 10.47 & 84767. \\
\hline 10.02 & 72126. \\
\hline 10.15 & 71840. \\
\hline 10.29 & 71112. \\
\hline 9.90 & 59313. \\
\hline 10.01 & 58686. \\
\hline 10.09 & 58305. \\
\hline 9.55 & 47596. \\
\hline 9.57 & 46712. \\
\hline 9.55 & 45620. \\
\hline 9.01 & 37906. \\
\hline 9.08 & 36661. \\
\hline 9.10 & 36176. \\
\hline 8.39 & 29238. \\
\hline 8.36 & 28351. \\
\hline 8.40 & 28239. \\
\hline 7.71 & 22604. \\
\hline 7.67 & 22048. \\
\hline 7.68 & 21903. \\
\hline 6.55 & 15368. \\
\hline 6.38 & 14521. \\
\hline 6.42 & 14666. \\
\hline 5.11 & 11589. \\
\hline 4.95 & 11253. \\
\hline 4.92 & 11161. \\
\hline 3.11 & 6405. \\
\hline 2.84 & 3111. \\
\hline 11.89 & 101733. \\
\hline 11.79 & 101684. \\
\hline 11.67 & 101830. \\
\hline 11.15 & 90046. \\
\hline 11.04 & 88356. \\
\hline 11.02 & 89751. \\
\hline 10.46 & 77202. \\
\hline 10.48 & 76672. \\
\hline 10.51 & 76540. \\
\hline 10.10 & 66977. \\
\hline 10.16 & 66239. \\
\hline 10.20 & 65987. \\
\hline 9.76 & 56010. \\
\hline 9.80 & 55725. \\
\hline
\end{tabular}

\begin{tabular}{|c|c|}
\hline 9.86 & 54988. \\
\hline 9.39 & 45602. \\
\hline 9.46 & 44515. \\
\hline 9.55 & 44037. \\
\hline 9.13 & 36980. \\
\hline 9.38 & 38216. \\
\hline 9.59 & 39938. \\
\hline 8.45 & 26181. \\
\hline 8.45 & 25627. \\
\hline 8.46 & 25629. \\
\hline 7.77 & 21164. \\
\hline 7.73 & 20620. \\
\hline 7.68 & 20195. \\
\hline 6.33 & 13437. \\
\hline 6.29 & 13235. \\
\hline 6.19 & 12748. \\
\hline 4.93 & 10279. \\
\hline 4.66 & 9801. \\
\hline 4.55 & 9475. \\
\hline 2.94 & 5860. \\
\hline 2.91 & 5683. \\
\hline 11.45 & 91666. \\
\hline 11.34 & 91714. \\
\hline 11.23 & 91753. \\
\hline 10.56 & 77318. \\
\hline 10.46 & 76340. \\
\hline 10.52 & 78265. \\
\hline 10.06 & 68178. \\
\hline 10.19 & 68474. \\
\hline 10.23 & 68618. \\
\hline 9.70 & 56961. \\
\hline 9.75 & 56300. \\
\hline 9.82 & 56231. \\
\hline 9.30 & 45676. \\
\hline 9.40 & 44727. \\
\hline 9.53 & 44110. \\
\hline 9.01 & 36013. \\
\hline 9.04 & 34915. \\
\hline 9.09 & 34495. \\
\hline 8.44 & 26712. \\
\hline 8.44 & 25236. \\
\hline 8.42 & 24810. \\
\hline 7.79 & 20439. \\
\hline 7.75 & 19967. \\
\hline 7.71 & 19668. \\
\hline 6.91 & 14587. \\
\hline 6.67 & 13541. \\
\hline 6.73 & 13864. \\
\hline 5.52 & 11737. \\
\hline 5.56 & 11862. \\
\hline 5.54 & 11668. \\
\hline 3.44 & 6101. \\
\hline 3.09 & 5904. \\
\hline 10.60 & 107879. \\
\hline 10.42 & 108444. \\
\hline 10.26 & 109251. \\
\hline 9.75 & 99210. \\
\hline 9.68 & 98497. \\
\hline 9.65 & 98550. \\
\hline 9.30 & 87155. \\
\hline 9.36 & 86508. \\
\hline
\end{tabular}




\begin{tabular}{|c|c|}
\hline 9.43 & 86291. \\
\hline 9.26 & 77012. \\
\hline 9.44 & 77827. \\
\hline 9.67 & 80041. \\
\hline 9.43 & 67781. \\
\hline 9.58 & 67154. \\
\hline 9.71 & 66848. \\
\hline 9.11 & 50344. \\
\hline 9.21 & 49092. \\
\hline 9.29 & 48770. \\
\hline 8.66 & 37631. \\
\hline 8.65 & 34900. \\
\hline 8.70 & 34541. \\
\hline 8.18 & 27567. \\
\hline 8.19 & 27088. \\
\hline 8.20 & 26988. \\
\hline 7.46 & 20973. \\
\hline 7.42 & 20448. \\
\hline 7.37 & 19403. \\
\hline 6.18 & 13122. \\
\hline 6.00 & 12482. \\
\hline 5.97 & 12318. \\
\hline 4.42 & 9059. \\
\hline 4.17 & 8734. \\
\hline 4.05 & 8437. \\
\hline 3.12 & 6268. \\
\hline 2.98 & 6060. \\
\hline 11.73 & 117032. \\
\hline 11.64 & 117390. \\
\hline 11.50 & 117533. \\
\hline 10.97 & 108167. \\
\hline 10.79 & 107370. \\
\hline 10.60 & 108217. \\
\hline 9.99 & 95594. \\
\hline 9.90 & 94709. \\
\hline 9.87 & 94455. \\
\hline 9.47 & 83541. \\
\hline 9.51 & 82936. \\
\hline 9.59 & 82942. \\
\hline 9.35 & 72226. \\
\hline 9.44 & 71371. \\
\hline 9.54 & 70749. \\
\hline 9.11 & 56067. \\
\hline 9.18 & 52366. \\
\hline 9.28 & 51504. \\
\hline 9.01 & 43638. \\
\hline 9.13 & 43863. \\
\hline 9.24 & 44304. \\
\hline 8.55 & 34211. \\
\hline 8.72 & 33827. \\
\hline 8.73 & 33382. \\
\hline 7.88 & 24584. \\
\hline 7.86 & 23757. \\
\hline 7.81 & 22969. \\
\hline 6.93 & 17068. \\
\hline 6.86 & 16511. \\
\hline 6.88 & 16540. \\
\hline 6.04 & 12459. \\
\hline 5.87 & 11933. \\
\hline 5.90 & 12034. \\
\hline 4.83 & 10172. \\
\hline 4.50 & 9537. \\
\hline 4.45 & 9405. \\
\hline 3.11 & 6190. \\
\hline 2.91 & 5837. \\
\hline
\end{tabular}

\section{\begin{tabular}{|l|l|}
\hline 2.87 & 5708. \\
\hline
\end{tabular} \\ R134a/RL68H2Cu (99/1) File: RL2Cu1.dat}

\begin{tabular}{|c|c|}
\hline $\begin{array}{c}|c| \\
(\mathrm{K})\end{array}$ & $\begin{array}{c}q " \\
\left(\mathrm{~W} / \mathrm{m}^{2}\right)\end{array}$ \\
\hline 15.57 & 90431. \\
\hline 15.60 & 89536. \\
\hline 15.66 & 90451. \\
\hline 15.19 & 77293. \\
\hline 15.36 & 76117. \\
\hline 15.46 & 75578. \\
\hline 14.88 & 65611. \\
\hline 14.97 & 64785. \\
\hline 15.02 & 64399. \\
\hline 14.27 & 54909. \\
\hline 14.31 & 53920. \\
\hline 14.33 & 53449. \\
\hline 13.46 & 45308. \\
\hline 13.53 & 45245. \\
\hline 13.81 & 46823. \\
\hline 12.51 & 36970. \\
\hline 12.83 & 38198. \\
\hline 13.12 & 39595. \\
\hline 11.44 & 29649. \\
\hline 11.46 & 28844. \\
\hline 11.52 & 28830. \\
\hline 10.22 & 22234. \\
\hline 10.13 & 21521. \\
\hline 10.09 & 21323. \\
\hline 9.06 & 16960. \\
\hline 8.87 & 16071. \\
\hline 8.73 & 15661. \\
\hline 7.57 & 12077. \\
\hline 7.48 & 11769. \\
\hline 7.41 & 11500. \\
\hline 5.63 & 8947. \\
\hline 5.44 & 8679. \\
\hline 5.39 & 8522. \\
\hline 3.69 & 5407. \\
\hline 3.35 & 5187. \\
\hline 13.97 & 91247. \\
\hline 14.27 & 91504. \\
\hline 14.42 & 90861. \\
\hline 13.96 & 77913. \\
\hline 14.05 & 76767. \\
\hline 14.12 & 76044. \\
\hline 13.59 & 65042. \\
\hline 13.78 & 63894. \\
\hline 13.91 & 63451. \\
\hline 13.40 & 55572. \\
\hline 13.47 & 54881. \\
\hline 13.52 & 54406. \\
\hline 12.75 & 46400. \\
\hline 12.79 & 45800. \\
\hline 12.82 & 45531. \\
\hline 11.92 & 37861. \\
\hline 11.95 & 37381. \\
\hline 11.95 & 37149. \\
\hline 10.90 & 29101. \\
\hline 11.09 & 29545. \\
\hline 9.84 & 30509. \\
\hline & 21877. \\
\hline
\end{tabular}

\begin{tabular}{|c|c|}
\hline & 21468. \\
\hline 9.84 & 21408. \\
\hline 9.87 & 15935. \\
\hline 8.66 & 15496. \\
\hline 8.59 & 15273. \\
\hline 8.55 & 11730. \\
\hline 7.21 & 11391. \\
\hline 7.03 & 11286. \\
\hline 7.03 & 8962. \\
\hline 5.35 & 8685. \\
\hline 5.10 & 8536. \\
\hline 5.04 & 5823. \\
\hline 3.64 & 5601. \\
\hline 3.32 & 88452. \\
\hline 13.98 & 87820. \\
\hline 14.00 & 87230. \\
\hline 14.00 & 72350. \\
\hline 13.33 & 70518. \\
\hline 13.43 & 69346. \\
\hline 13.58 & 60665. \\
\hline 13.23 & 59550. \\
\hline 13.38 & 5926. \\
\hline 13.54 & 50264. \\
\hline 13.05 & 596. \\
\hline 13.15 & 49805. \\
\hline 13.25 & 49590. \\
\hline 12.57 & 42549. \\
\hline 12.60 & 41564. \\
\hline 12.62 & 41093. \\
\hline 11.64 & 33743. \\
\hline 11.68 & 33187. \\
\hline 11.70 & 32891. \\
\hline 10.84 & 27163. \\
\hline 10.81 & 26333. \\
\hline 10.84 & 26132. \\
\hline 9.79 & 20732. \\
\hline 9.78 & 20404. \\
\hline 9.77 & 20199. \\
\hline 8.78 & 17139. \\
\hline 8.64 & 16393. \\
\hline 8.64 & 15480. \\
\hline 7.23 & 11842. \\
\hline 7.04 & 11461. \\
\hline 6.99 & 11202. \\
\hline 5.61 & 9769. \\
\hline 5.43 & 9703. \\
\hline 5.49 & 9771. \\
\hline 3.91 & 6246. \\
\hline 3.60 & 6014. \\
\hline 15.20 & 100449. \\
\hline 15.30 & 99935. \\
\hline 15.33 & 99467. \\
\hline 14.77 & 86042. \\
\hline 14.71 & 84652. \\
\hline 14.69 & 84407. \\
\hline 14.22 & 76082. \\
\hline 14.36 & 75210. \\
\hline 14.23 & 7443. \\
\hline 14.36 & 65033. \\
\hline 14.48 & 64379. \\
\hline 14.05 & 56282. \\
\hline 14.18 & 55526. \\
\hline 14.27 & 54977. \\
\hline 13.47 & 46288. \\
\hline 13.49 & 45529. \\
\hline & \\
\hline
\end{tabular}




\begin{tabular}{|c|c|}
\hline 13.55 & 45048. \\
\hline 12.63 & 37457. \\
\hline 12.65 & 36947. \\
\hline 12.84 & 37570. \\
\hline 11.96 & 31505. \\
\hline 11.99 & 31315. \\
\hline 12.02 & 31216. \\
\hline 10.90 & 24617. \\
\hline 10.85 & 24136. \\
\hline 10.84 & 23907. \\
\hline 9.87 & 19581. \\
\hline 9.75 & 19122. \\
\hline 9.80 & 19122. \\
\hline 7.95 & 14104. \\
\hline 7.88 & 13778. \\
\hline 7.87 & 13608. \\
\hline 6.16 & 9303. \\
\hline 5.92 & 10850. \\
\hline 5.91 & 10749. \\
\hline 3.87 & 6425. \\
\hline 3.69 & 6256. \\
\hline 14.18 & 97100. \\
\hline 14.80 & 95412. \\
\hline 14.96 & 94812. \\
\hline 14.50 & 80208. \\
\hline 14.50 & 79513. \\
\hline 14.44 & 79686. \\
\hline 14.14 & 70883. \\
\hline 14.32 & 70088. \\
\hline 14.45 & 68986. \\
\hline 13.94 & 58383. \\
\hline 13.87 & 55577. \\
\hline 14.08 & 55668. \\
\hline 13.62 & 49628. \\
\hline 13.83 & 50425. \\
\hline 13.96 & 50865. \\
\hline 12.95 & 41690. \\
\hline 13.01 & 41396. \\
\hline 13.09 & 41393. \\
\hline 12.05 & 34383. \\
\hline 12.04 & 33848. \\
\hline 12.04 & 33455. \\
\hline 10.77 & 25856. \\
\hline 10.75 & 25315. \\
\hline 10.72 & 24996. \\
\hline 9.78 & 20872. \\
\hline 9.68 & 20160. \\
\hline 9.63 & 19972. \\
\hline 8.57 & 15822. \\
\hline 8.47 & 15502. \\
\hline 8.53 & 15514. \\
\hline 7.12 & 12229. \\
\hline 6.81 & 10390. \\
\hline 6.83 & 10389. \\
\hline 5.08 & 9467. \\
\hline 5.01 & 9246. \\
\hline 16.26 & 97545. \\
\hline 16.35 & 97208. \\
\hline 16.34 & 96890. \\
\hline 15.77 & 85720. \\
\hline 15.68 & 85361. \\
\hline 15.56 & 85473. \\
\hline 14.98 & 76110. \\
\hline 15.29 & 74304. \\
\hline 15.52 & 73703. \\
\hline
\end{tabular}

\begin{tabular}{|c|c|}
\hline 15.23 & 64687. \\
\hline 15.29 & 63606. \\
\hline 15.32 & 63154. \\
\hline 14.62 & 55086. \\
\hline 14.66 & 54331. \\
\hline 14.73 & 54141. \\
\hline 13.90 & 45903. \\
\hline 13.95 & 45315. \\
\hline 14.01 & 44879. \\
\hline 13.16 & 37982. \\
\hline 13.22 & 37563. \\
\hline 13.18 & 37096. \\
\hline 11.98 & 29848. \\
\hline 12.03 & 29895. \\
\hline 12.24 & 30636. \\
\hline 11.07 & 24698. \\
\hline 11.07 & 24434. \\
\hline 11.06 & 24106. \\
\hline 9.83 & 19221. \\
\hline 9.75 & 18693. \\
\hline 9.72 & 18488. \\
\hline 8.39 & 14212. \\
\hline 8.27 & 14690. \\
\hline 8.21 & 14517. \\
\hline 5.74 & 10004. \\
\hline 5.45 & 9638. \\
\hline 13.63 & 111999. \\
\hline 13.64 & 110201. \\
\hline 13.67 & 110012. \\
\hline 13.19 & 99108. \\
\hline 13.15 & 98706. \\
\hline 13.10 & 98779. \\
\hline 12.55 & 88573. \\
\hline 12.73 & 87504. \\
\hline 12.93 & 86551. \\
\hline 12.62 & 76206. \\
\hline 12.79 & 74919. \\
\hline 12.96 & 73811. \\
\hline 12.58 & 64587. \\
\hline 12.72 & 63614. \\
\hline 12.82 & 63088. \\
\hline 12.21 & 53589. \\
\hline 12.36 & 52857. \\
\hline 12.44 & 51889. \\
\hline 11.84 & 44165. \\
\hline 11.90 & 43596. \\
\hline 11.81 & 42042. \\
\hline 10.97 & 34485. \\
\hline 11.17 & 34870. \\
\hline 11.33 & 35648. \\
\hline 10.28 & 28813. \\
\hline 10.32 & 28398. \\
\hline 10.35 & 28000. \\
\hline 9.23 & 22779. \\
\hline 9.20 & 22252. \\
\hline 9.16 & 21948. \\
\hline 8.15 & 17778. \\
\hline 8.06 & 17311. \\
\hline 8.09 & 17308. \\
\hline 4.07 & 6869. \\
\hline 3.50 & 6141. \\
\hline 13.06 & 113088. \\
\hline 13.25 & 113437. \\
\hline 13.34 & 113001. \\
\hline 12.89 & 101946. \\
\hline
\end{tabular}

\begin{tabular}{|c|c|}
\hline 12.86 & 101267. \\
\hline 12.79 & 101821. \\
\hline 12.21 & 92085. \\
\hline 12.47 & 89656. \\
\hline 12.77 & 88020. \\
\hline 12.40 & 76899. \\
\hline 12.58 & 75429. \\
\hline 12.69 & 74752. \\
\hline 12.24 & 66222. \\
\hline 12.31 & 65415. \\
\hline 12.36 & 65183. \\
\hline 11.60 & 55652. \\
\hline 11.63 & 54760. \\
\hline 11.76 & 55353. \\
\hline 10.71 & 44622. \\
\hline 10.73 & 37470. \\
\hline 10.69 & 36501. \\
\hline 9.84 & 30072. \\
\hline 9.95 & 29869. \\
\hline 10.00 & 29957. \\
\hline 8.69 & 22283. \\
\hline 8.59 & 21474. \\
\hline 8.62 & 21402. \\
\hline 7.27 & 15545. \\
\hline 7.01 & 14656. \\
\hline 6.95 & 14331. \\
\hline 14.82 & 104337. \\
\hline 14.92 & 104090. \\
\hline 14.94 & 104079. \\
\hline 14.17 & 93011. \\
\hline 14.18 & 92405. \\
\hline 15.86 & 98960. \\
\hline 15.90 & 99047. \\
\hline 15.84 & 99525. \\
\hline 15.71 & 98751. \\
\hline 15.23 & 91161. \\
\hline 14.99 & 86850. \\
\hline 14.71 & 80979. \\
\hline 14.80 & 75557. \\
\hline & \\
\hline
\end{tabular}

R134a/RL68H2Cu (98/2) File: RL2Cu2.dat

\begin{tabular}{|c|c|}
\hline $\begin{array}{c}\Delta T_{\mathrm{s}} \\
(\mathrm{K})\end{array}$ & $\begin{array}{c}q^{\prime \prime} \\
\left(\mathrm{W} / \mathrm{m}^{2}\right)\end{array}$ \\
\hline 14.90 & 102684. \\
\hline 14.87 & 102593. \\
\hline 14.95 & 102828. \\
\hline 14.24 & 94679. \\
\hline 14.32 & 93683. \\
\hline 14.42 & 93407. \\
\hline 13.86 & 84447. \\
\hline 13.97 & 83987. \\
\hline 14.13 & 83943. \\
\hline 13.55 & 76976. \\
\hline 13.59 & 76293. \\
\hline 13.57 & 73727. \\
\hline 13.03 & 66472. \\
\hline 13.03 & 65734. \\
\hline 13.15 & 65565. \\
\hline 12.38 & 55631. \\
\hline 12.25 & 54820. \\
\hline 12.24 & 53255. \\
\hline 11.67 & 45974. \\
\hline & \\
\hline
\end{tabular}




\begin{tabular}{|c|c|}
\hline 11.79 & 46527. \\
\hline 12.01 & 47550. \\
\hline 11.07 & 36645. \\
\hline 11.08 & 36293. \\
\hline 11.16 & 35968. \\
\hline 10.40 & 28366. \\
\hline 10.36 & 27808. \\
\hline 10.44 & 27765. \\
\hline 9.47 & 20917. \\
\hline 9.46 & 20770. \\
\hline 9.46 & 20431. \\
\hline 8.38 & 15638. \\
\hline 8.30 & 15198. \\
\hline 8.26 & 14983. \\
\hline 6.27 & 9837. \\
\hline 6.01 & 9372. \\
\hline 16.52 & 111885. \\
\hline 16.58 & 111998. \\
\hline 16.72 & 111872. \\
\hline 16.06 & 101352. \\
\hline 16.17 & 99547. \\
\hline 16.31 & 98764. \\
\hline 15.63 & 88273. \\
\hline 15.71 & 87408. \\
\hline 15.82 & 86758. \\
\hline 15.27 & 78576. \\
\hline 15.33 & 78079. \\
\hline 15.50 & 74860. \\
\hline 14.64 & 68441. \\
\hline 14.61 & 64098. \\
\hline 14.63 & 63421. \\
\hline 13.41 & 52030. \\
\hline 13.37 & 51699. \\
\hline 13.41 & 51409. \\
\hline 12.54 & 42904. \\
\hline 12.52 & 42782. \\
\hline 12.44 & 41645. \\
\hline 11.76 & 34712. \\
\hline 11.79 & 34490. \\
\hline 12.03 & 35616. \\
\hline 10.87 & 26229. \\
\hline 10.81 & 25939. \\
\hline 10.83 & 25845. \\
\hline 9.11 & 17691. \\
\hline 8.96 & 17044. \\
\hline 8.91 & 16698. \\
\hline 7.07 & 12051. \\
\hline 6.89 & 11762. \\
\hline 6.84 & 11529. \\
\hline 4.68 & 6221. \\
\hline 4.39 & 5925. \\
\hline 14.88 & 106368. \\
\hline 15.01 & 105716. \\
\hline 15.18 & 105067. \\
\hline 14.53 & 95385. \\
\hline 14.44 & 92577. \\
\hline 14.59 & 91898. \\
\hline 14.14 & 84049. \\
\hline 14.35 & 84502. \\
\hline 14.52 & 84303. \\
\hline 13.72 & 74102. \\
\hline 13.75 & 73407. \\
\hline 13.80 & 72763. \\
\hline 12.88 & 62496. \\
\hline 12.84 & 62173. \\
\hline
\end{tabular}

\begin{tabular}{|c|c|}
\hline 12.87 & 61855. \\
\hline 12.26 & 54233. \\
\hline 12.24 & 54306. \\
\hline 12.33 & 54613. \\
\hline 11.52 & 43697. \\
\hline 11.59 & 41981. \\
\hline 11.62 & 41216. \\
\hline 10.86 & 32399. \\
\hline 10.88 & 32354. \\
\hline 10.92 & 31999. \\
\hline 9.93 & 24073. \\
\hline 9.91 & 24682. \\
\hline 9.88 & 24197. \\
\hline 8.94 & 18895. \\
\hline 8.85 & 18242. \\
\hline 8.87 & 17989. \\
\hline 7.17 & 11779. \\
\hline 6.88 & 12447. \\
\hline 6.89 & 12323. \\
\hline 4.53 & 5949. \\
\hline 4.13 & 5892. \\
\hline 15.34 & 97913. \\
\hline 15.29 & 99656. \\
\hline 15.39 & 99973. \\
\hline 14.80 & 91273. \\
\hline 14.85 & 89705. \\
\hline 14.93 & 88944. \\
\hline 13.98 & 76410. \\
\hline 13.92 & 74810. \\
\hline 13.99 & 74085. \\
\hline 13.28 & 64939. \\
\hline 13.42 & 65858. \\
\hline 13.55 & 67458. \\
\hline 12.71 & 58221. \\
\hline 12.73 & 57805. \\
\hline 12.76 & 56949. \\
\hline 11.91 & 48494. \\
\hline 11.93 & 48169. \\
\hline 11.94 & 47695. \\
\hline 11.36 & 41047. \\
\hline 11.38 & 41727. \\
\hline 11.40 & 41302. \\
\hline 10.48 & 30798. \\
\hline 10.43 & 30106. \\
\hline 10.43 & 29651. \\
\hline 9.65 & 23284. \\
\hline 9.59 & 22507. \\
\hline 9.56 & 22089. \\
\hline 8.54 & 17384. \\
\hline 8.55 & 17243. \\
\hline 8.58 & 17287. \\
\hline 7.04 & 11264. \\
\hline 6.91 & 10815. \\
\hline 6.86 & 10669. \\
\hline 4.30 & 5641. \\
\hline 4.06 & 5545. \\
\hline 14.02 & 101904. \\
\hline 14.06 & 101203. \\
\hline 14.13 & 99544. \\
\hline 13.72 & 90059. \\
\hline 13.98 & 91461. \\
\hline 14.30 & 93656. \\
\hline 13.86 & 79065. \\
\hline 14.09 & 80676. \\
\hline 14.35 & 81913. \\
\hline
\end{tabular}

\begin{tabular}{|c|c|}
\hline 13.15 & 68612 \\
\hline 13.17 & 69390. \\
\hline 13.25 & 70321. \\
\hline 12.11 & 57108 \\
\hline 12.07 & 57088 \\
\hline 12.14 & 56792 \\
\hline 11.40 & 47127. \\
\hline 11.31 & 44581. \\
\hline 10.67 & 36995. \\
\hline 10.44 & 31626. \\
\hline 10.52 & 32029 \\
\hline 10.64 & 33136. \\
\hline 9.54 & 23685 \\
\hline 9.47 & 22610. \\
\hline 9.48 & 21944 \\
\hline 8.72 & 18905 \\
\hline 8.71 & 17851. \\
\hline 8.67 & 17308 \\
\hline 7.14 & 13432 \\
\hline 7.23 & 12150. \\
\hline 7.38 & 12554 \\
\hline 5.33 & 7848. \\
\hline 5.17 & 7786. \\
\hline 14.91 & 87968. \\
\hline 15.06 & 87572 \\
\hline 15.21 & 86930. \\
\hline 14.84 & 80539 \\
\hline 14.79 & 77125 \\
\hline 14.88 & 76599 \\
\hline 14.23 & 68151. \\
\hline 14.20 & 67968. \\
\hline 14.23 & 67973. \\
\hline 13.41 & 59512 \\
\hline 13.38 & 59128. \\
\hline 13.39 & 59355. \\
\hline 12.61 & 51825 \\
\hline 12.57 & 52099 \\
\hline 12.62 & 52518 \\
\hline 11.75 & 44030 \\
\hline 11.77 & 44021. \\
\hline 11.85 & 44163. \\
\hline 10.91 & 35135 \\
\hline 10.93 & 34971. \\
\hline 10.98 & 34815 \\
\hline 10.11 & 27469 \\
\hline 10.16 & 27220. \\
\hline 10.18 & 27221. \\
\hline 9.21 & 20416. \\
\hline 9.16 & 20221. \\
\hline 9.21 & 20318. \\
\hline 7.94 & 14252 \\
\hline 7.90 & 14795 \\
\hline 7.91 & 14755 \\
\hline 6.68 & 12082 \\
\hline 6.63 & 11915. \\
\hline 6.56 & 11669 \\
\hline 4.27 & 5644. \\
\hline 4.08 & 5620. \\
\hline 3.99 & 5510. \\
\hline
\end{tabular}


Table 3 Number of test days and data points

\begin{tabular}{|c|c|c|}
\hline Fluid (\% mass fraction) & Number of days & Number of data points \\
\hline $\begin{array}{c}\text { R134a/RL68H2Cu (99.5/0.5) } \\
4.3 \mathrm{~K} \leq \Delta T_{\mathrm{s}} \leq 10.2 \mathrm{~K}\end{array}$ & 7 & 243 \\
\hline $\begin{array}{c}\mathrm{R} 134 \mathrm{a} / \mathrm{RL} 68 \mathrm{H} 2 \mathrm{Cu}(99 / 1) \\
4.7 \mathrm{~K} \leq \Delta T_{\mathrm{s}} \leq 11.3 \mathrm{~K}\end{array}$ & 9 & 291 \\
\hline $\mathrm{R} 134 \mathrm{a} / \mathrm{RL} 68 \mathrm{H} 2 \mathrm{Cu}(98 / 2)$ & 6 & 208 \\
$4.1 \mathrm{~K} \leq \Delta T_{\mathrm{s}} \leq 10.3 \mathrm{~K}$ & & \\
\hline
\end{tabular}

Table 4 Estimated parameters for cubic boiling curve fits for plain copper surface $\Delta T_{\mathrm{s}}=\mathrm{A}_{0}+\mathrm{A}_{1} q "+\mathrm{A}_{2} q^{\prime 2}+\mathrm{A}_{3} q^{\prime 3}$

$\Delta T_{\mathrm{s}}$ in Kelvin and $q$ " in $\mathrm{W} / \mathrm{m}^{2}$

\begin{tabular}{|c|c|c|c|c|}
\hline Fluid & $\mathrm{A}_{0}$ & $\mathrm{~A}_{1}$ & $\mathrm{~A}_{2}$ & $\mathrm{~A}_{3}$ \\
\hline $\mathrm{R} 134 \mathrm{a} / \mathrm{RL} 68 \mathrm{H} 2 \mathrm{Cu}(99.5 / 0.5)$ & & & & \\
$4.3 \mathrm{~K} \leq \Delta T_{\mathrm{s}} \leq 8.5 \mathrm{~K}$ & $-7.73305 \times 10^{-1}$ & $7.30718 \times 10^{-4}$ & $-1.90704 \times 10^{-8}$ & $1.65931 \times 10^{-13}$ \\
$8.5 \mathrm{~K} \leq \Delta T_{\mathrm{s}} \leq 10.2 \mathrm{~K}$ & 4.88641 & $1.77973 \times 10^{-4}$ & $-2.19853 \times 10^{-9}$ & $9.84361 \times 10^{-15}$ \\
\hline $\mathrm{R} 134 \mathrm{a} / \mathrm{RL} 68 \mathrm{H} 2 \mathrm{Cu}(99 / 1)$ & & & & \\
$4.7 \mathrm{~K} \leq \Delta T_{\mathrm{s}} \leq 9.5 \mathrm{~K}$ & -1.35217 & $9.95281 \times 10^{-4}$ & $-2.86155 \times 10^{-8}$ & $3.07861 \times 10^{-13}$ \\
$9.5 \mathrm{~K} \leq \Delta T_{\mathrm{s}} \leq 11.3 \mathrm{~K}$ & 4.66547 & $3.07933 \times 10^{-4}$ & $-3.31686 \times 10^{-9}$ & $1.21057 \times 10^{-14}$ \\
\hline $\mathrm{R} 134 \mathrm{a} / \mathrm{RL} 68 \mathrm{H} 2 \mathrm{Cu}(99 / 2)$ & & & & \\
$4.1 \mathrm{~K} \leq \Delta T_{\mathrm{s}} \leq 9.5 \mathrm{~K}$ & 1.13092 & $5.80570 \times 10^{-4}$ & $-5.24572 \times 10^{-9}$ & $-1.77277 \times 10^{-13}$ \\
$9.5 \mathrm{~K} \leq \Delta T_{\mathrm{s}} \leq 10.3 \mathrm{~K}$ & 7.13263 & $1.21866 \times 10^{-4}$ & $-2.70100 \times 10^{-10}$ & $-1.61515 \times 10^{-15}$ \\
\hline
\end{tabular}


Table 5 Residual standard deviation of $\Delta T_{\mathrm{s}}$

\begin{tabular}{|c|c|}
\hline Fluid & $u(\mathrm{~K})$ \\
\hline $\mathrm{R} 134 \mathrm{a} / \mathrm{RL} 68 \mathrm{H} 2 \mathrm{Cu}(99.5 / 0.5)$ & \\
$4.3 \mathrm{~K} \leq \Delta T_{\mathrm{s}} \leq 8.5 \mathrm{~K}$ & 0.30 \\
$8.5 \mathrm{~K} \leq \Delta T_{\mathrm{s}} \leq 10.2 \mathrm{~K}$ & 0.53 \\
\hline $\mathrm{R} 134 \mathrm{a} / \mathrm{RL} 68 \mathrm{H} 2 \mathrm{Cu}(99 / 1)$ & \\
$4.7 \mathrm{~K} \leq \Delta T_{\mathrm{s}} \leq 9.5 \mathrm{~K}$ & 0.49 \\
$9.5 \mathrm{~K} \leq \Delta T_{\mathrm{s}} \leq 11.3 \mathrm{~K}$ & 0.88 \\
\hline $\mathrm{R} 134 \mathrm{a} / \mathrm{RL} 68 \mathrm{H} 2 \mathrm{Cu}(99 / 2)$ & \\
$4.1 \mathrm{~K} \leq \Delta T_{\mathrm{s}} \leq 9.5 \mathrm{~K}$ & 0.20 \\
$9.5 \mathrm{~K} \leq \Delta T_{\mathrm{s}} \leq 10.3 \mathrm{~K}$ & 0.53 \\
\hline
\end{tabular}

Table 6 Average magnitude of $95 \%$ multi-use confidence interval for mean $T_{w}-T_{s}(K)$

\begin{tabular}{|c|c|}
\hline Fluid & $u(\mathrm{~K})$ \\
\hline $\mathrm{R} 134 \mathrm{a} / \mathrm{RL} 68 \mathrm{H} 2 \mathrm{Cu}(99.5 / 0.5)$ & \\
$4.3 \mathrm{~K} \leq \Delta T_{\mathrm{s}} \leq 8.5 \mathrm{~K}$ & 0.22 \\
$8.5 \mathrm{~K} \leq \Delta T_{\mathrm{s}} \leq 10.2 \mathrm{~K}$ & 0.26 \\
\hline $\mathrm{R} 134 \mathrm{a} / \mathrm{RL} 68 \mathrm{H} 2 \mathrm{Cu}(99 / 1)$ & \\
$4.7 \mathrm{~K} \leq \Delta T_{\mathrm{s}} \leq 9.5 \mathrm{~K}$ & 0.31 \\
$9.5 \mathrm{~K} \leq \Delta T_{\mathrm{s}} \leq 11.3 \mathrm{~K}$ & 0.37 \\
\hline $\mathrm{R} 134 \mathrm{a} / \mathrm{RL} 68 \mathrm{H} 2 \mathrm{Cu}(99 / 2)$ & \\
$4.1 \mathrm{~K} \leq \Delta T_{\mathrm{s}} \leq 9.5 \mathrm{~K}$ & 0.19 \\
$9.5 \mathrm{~K} \leq \Delta T_{\mathrm{s}} \leq 10.3 \mathrm{~K}$ & 0.28 \\
\hline
\end{tabular}




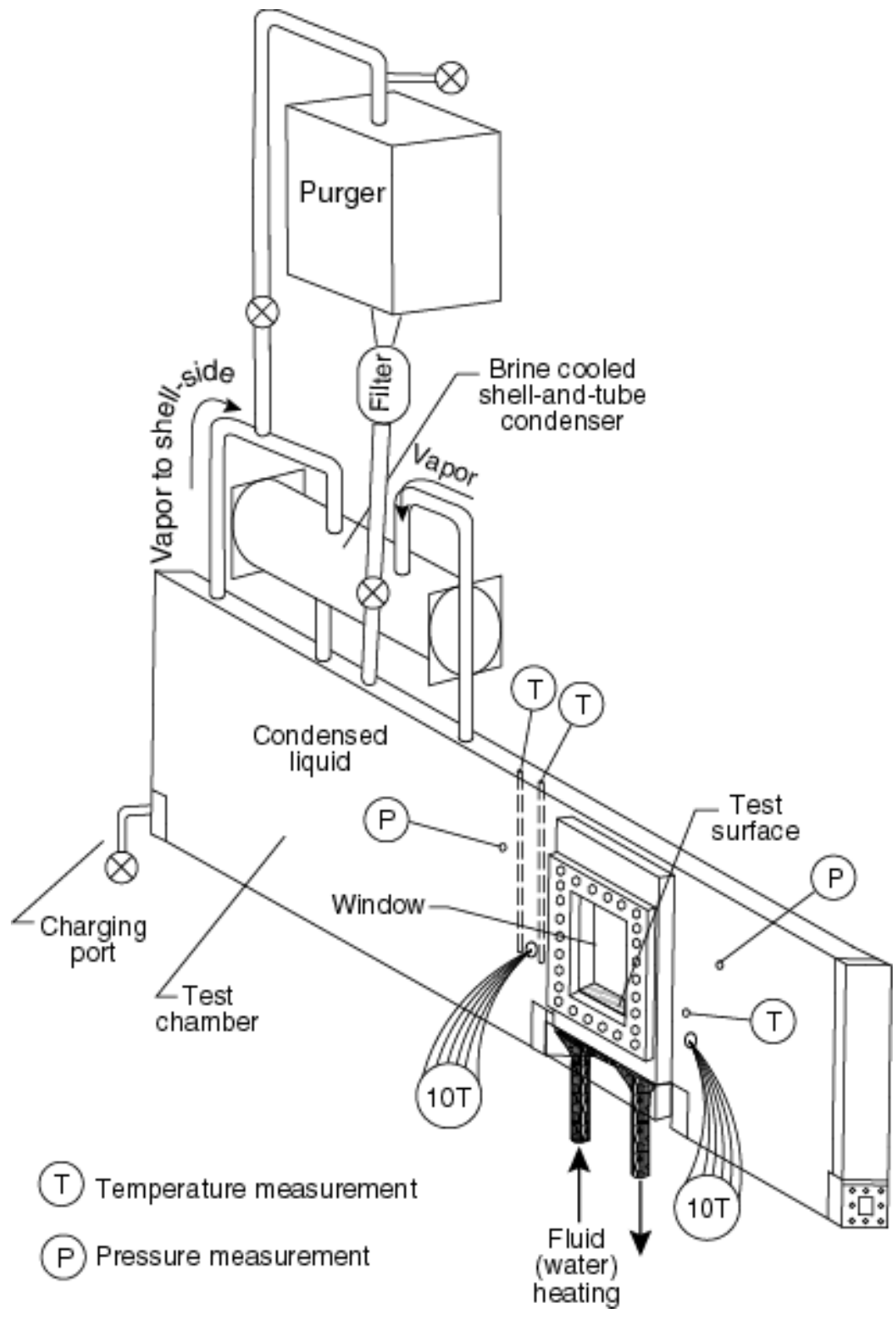

Fig. 1 Schematic of test apparatus 


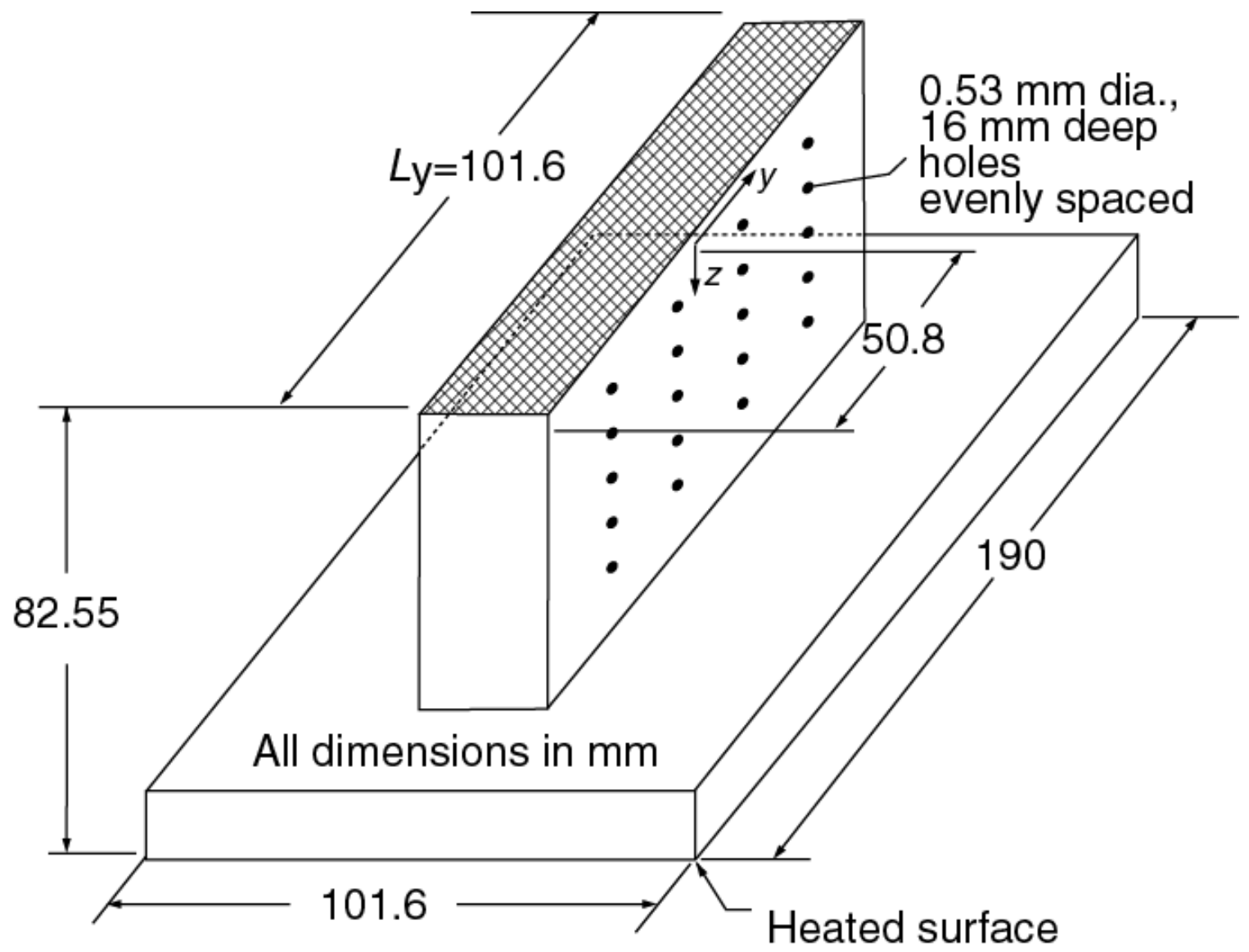

Fig. 2 OFHC copper flat test plate with cross-hatched surface and thermocouple coordinate system 


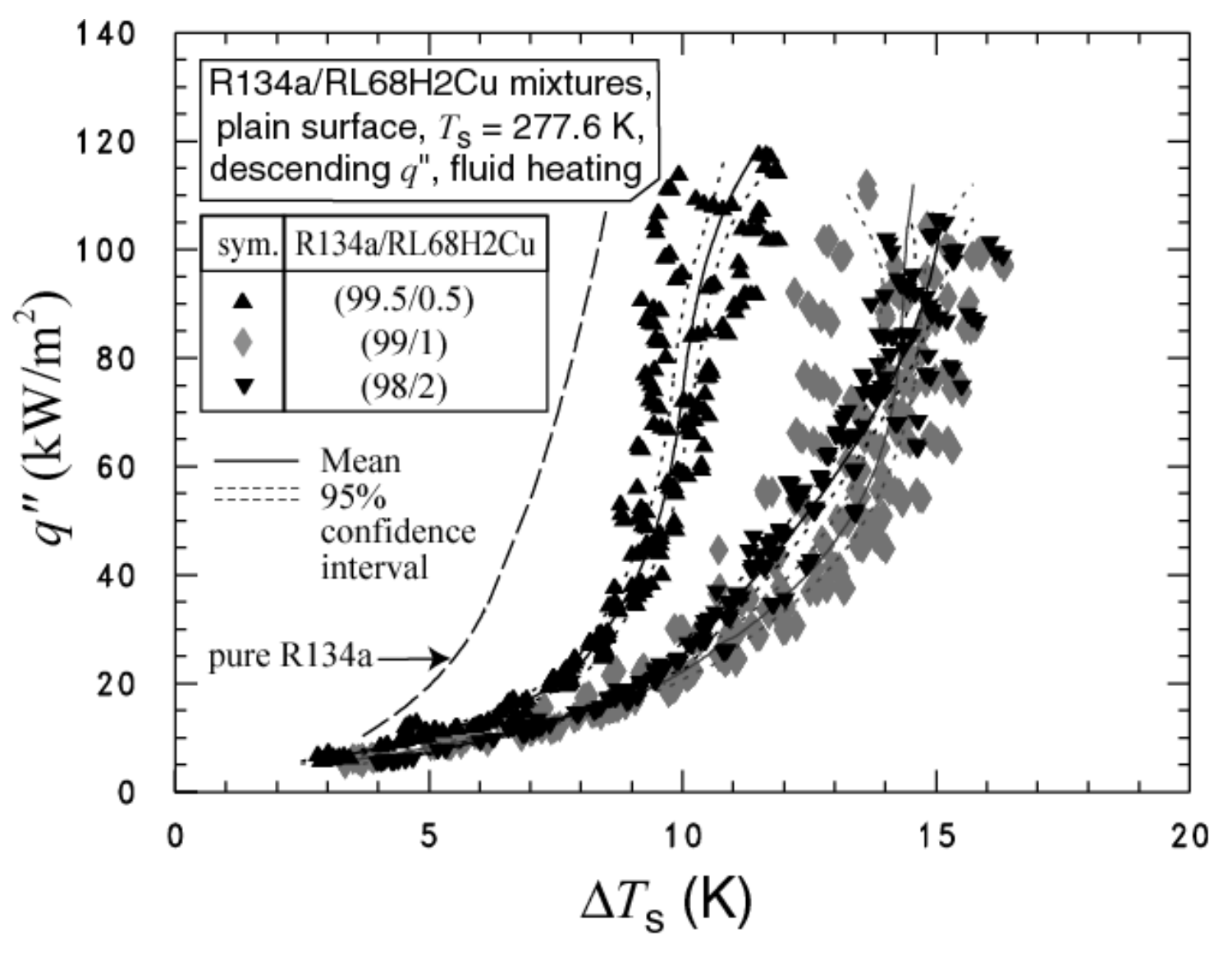

Fig. 3 R134a/RL68H with 2 \% volume $\mathrm{CuO}$ nanoparticle mixtures boiling curves for plain surface 


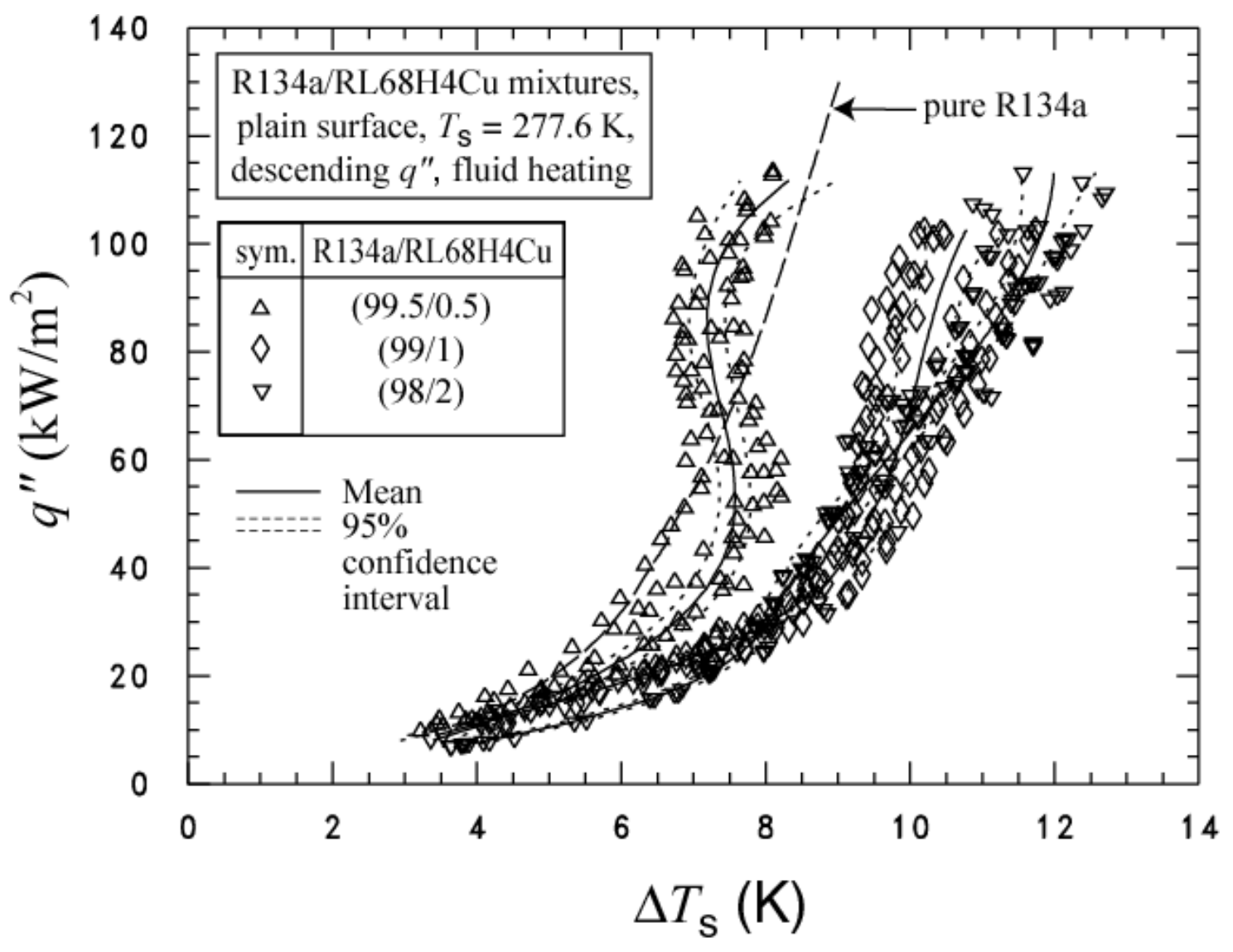

Fig. $4 \mathrm{R} 134 \mathrm{a} / \mathrm{RL} 68 \mathrm{H}$ with $4 \%$ volume $\mathrm{CuO}$ nanoparticle mixtures boiling curves for plain surface (Kedzierski and Gong, 2007) 


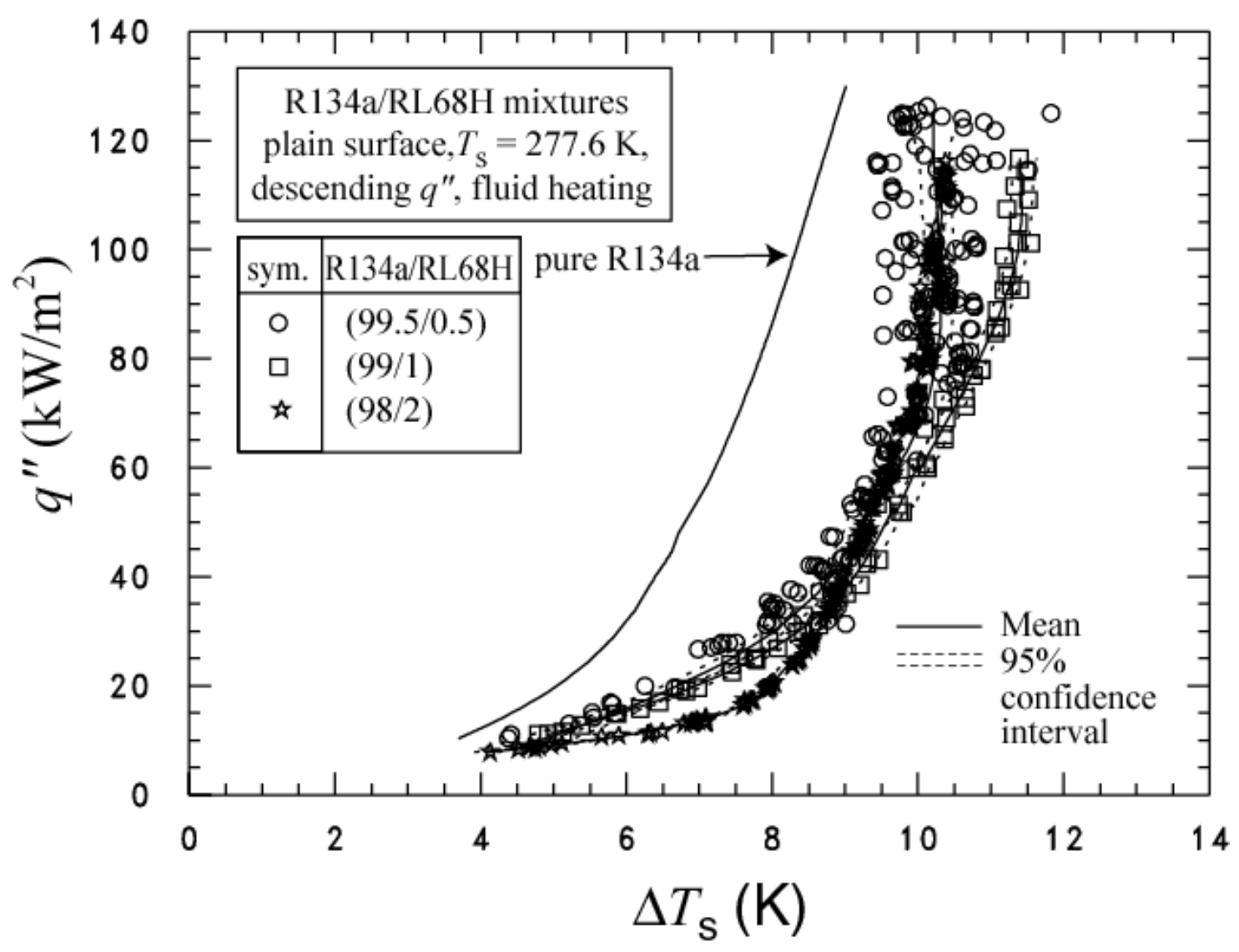

Fig. 5 R134a/RL68H mixtures boiling curves for plain surface (Kedzierski and Gong, 2007) 


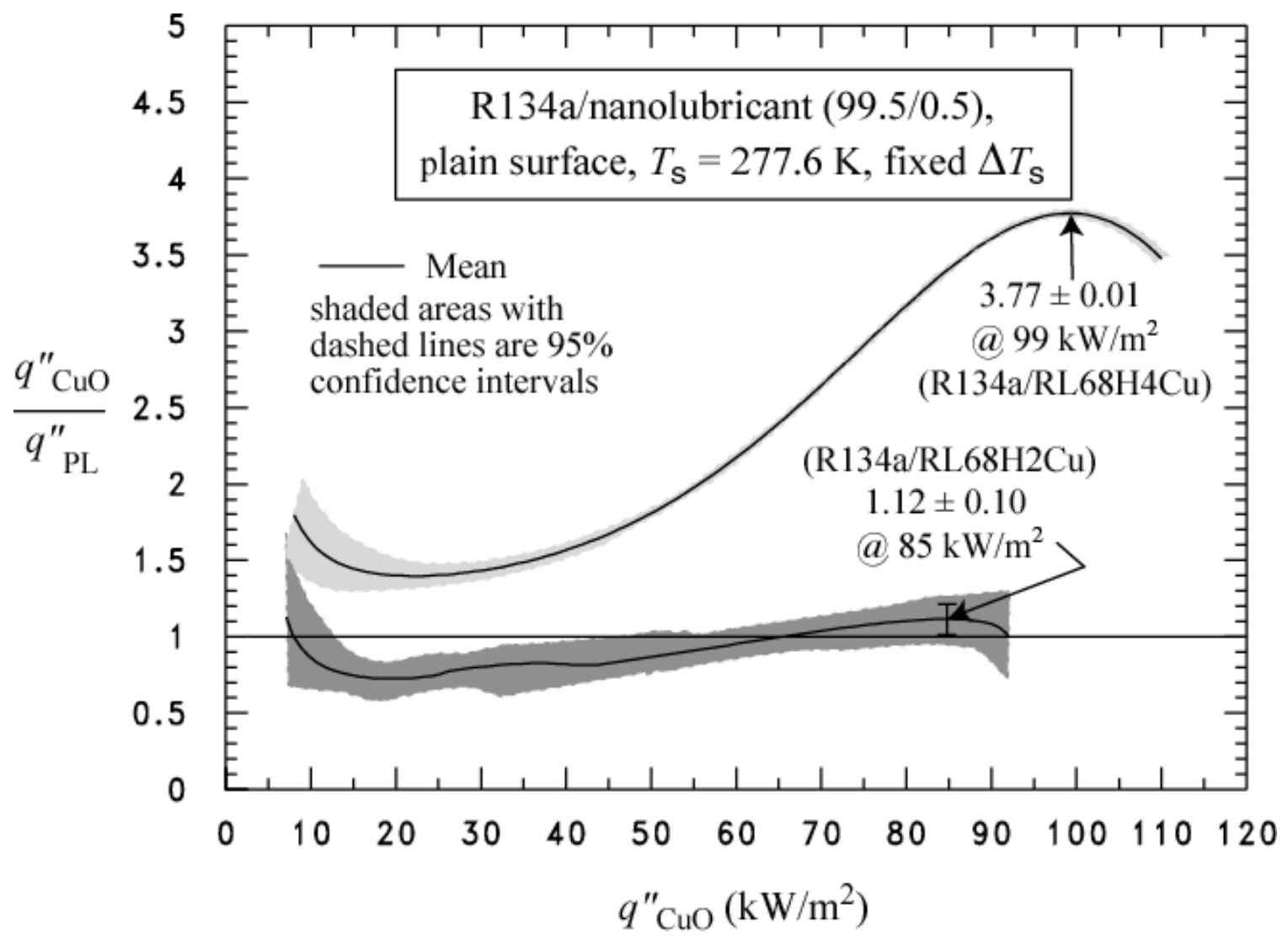

Fig. 6 Heat flux of R134a/RL68H mixtures with CuO nanoparticles relative to that of $\mathrm{R} 134 \mathrm{a} / \mathrm{RL68H}$ mixtures without $\mathrm{CuO}$ nanoparticles for the 99.5/0.5 composition 


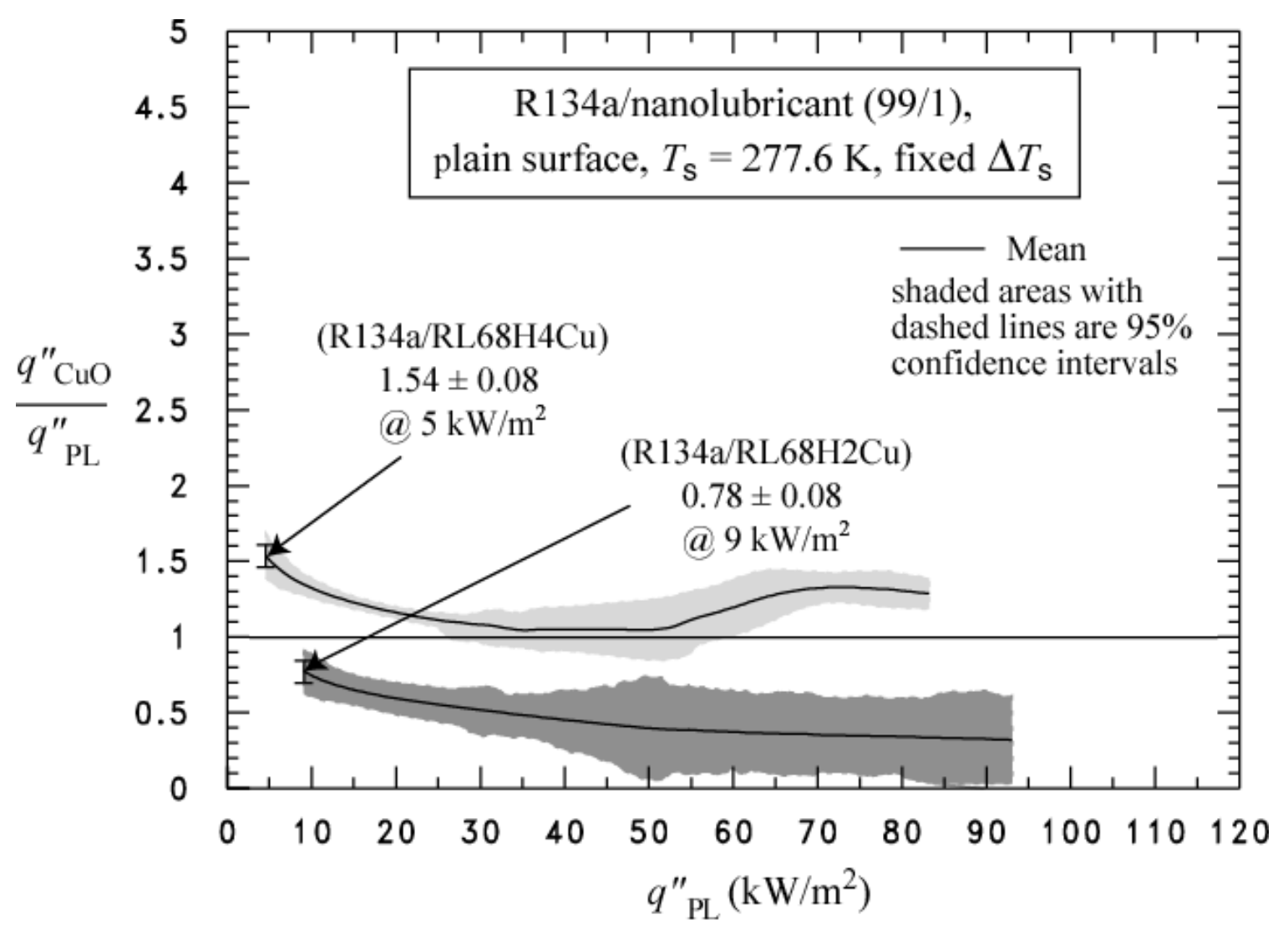

Fig. 7 Heat flux of R134a/RL68H mixtures with $\mathrm{CuO}$ nanoparticles relative to that of $\mathrm{R} 134 a / R L 68 H$ mixtures without $\mathrm{CuO}$ nanoparticles for the 99/1 composition 


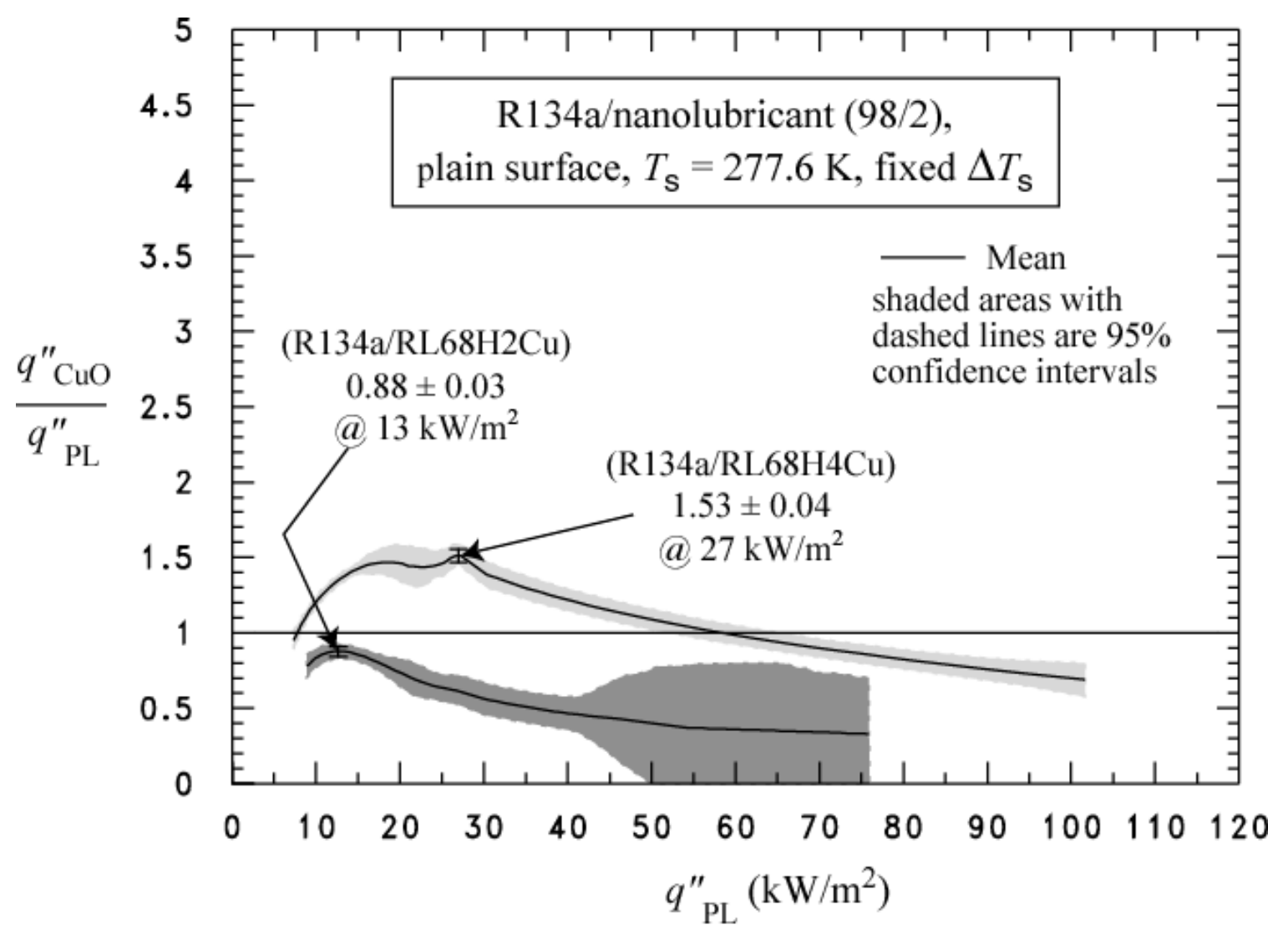

Fig. 8 Heat flux of R134a/RL68H mixtures with $\mathrm{CuO}$ nanoparticles relative to that of $\mathrm{R} 134 \mathrm{a} / \mathrm{RL} 68 \mathrm{H}$ mixtures without $\mathrm{CuO}$ nanoparticles for the $98 / 2$ composition 


\section{APPENDIX A: UNCERTAINTIES}

Figure A.1 shows the relative (percent) uncertainty of the heat flux $\left(U_{\mathrm{q}}\right.$ ) as a function of the heat flux. Figure A.2 shows the uncertainty of the wall temperature as a function of heat flux. The uncertainties shown in Figs. A.1 and A.2 are "within-run uncertainties." These do not include the uncertainties due to "between-run effects" or differences observed between tests taken on different days. The "within-run uncertainties" include only the random effects and uncertainties associated with one particular test. All other uncertainties reported in this study are "between-run uncertainties" which include all random effects such as surface past history or seeding.

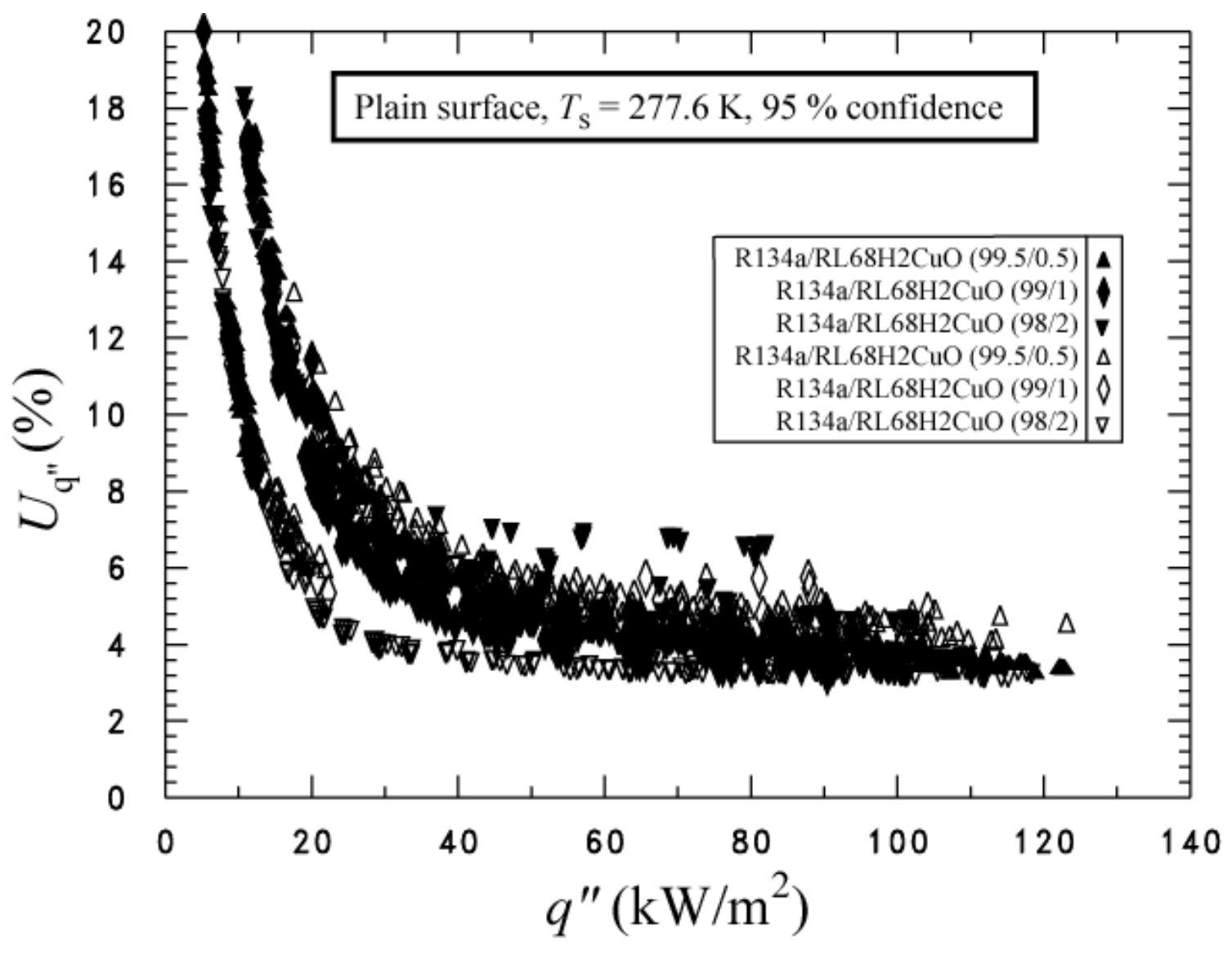

Fig. A.1 Expanded relative uncertainty in the measured heat flux at the $95 \%$ confidence level 


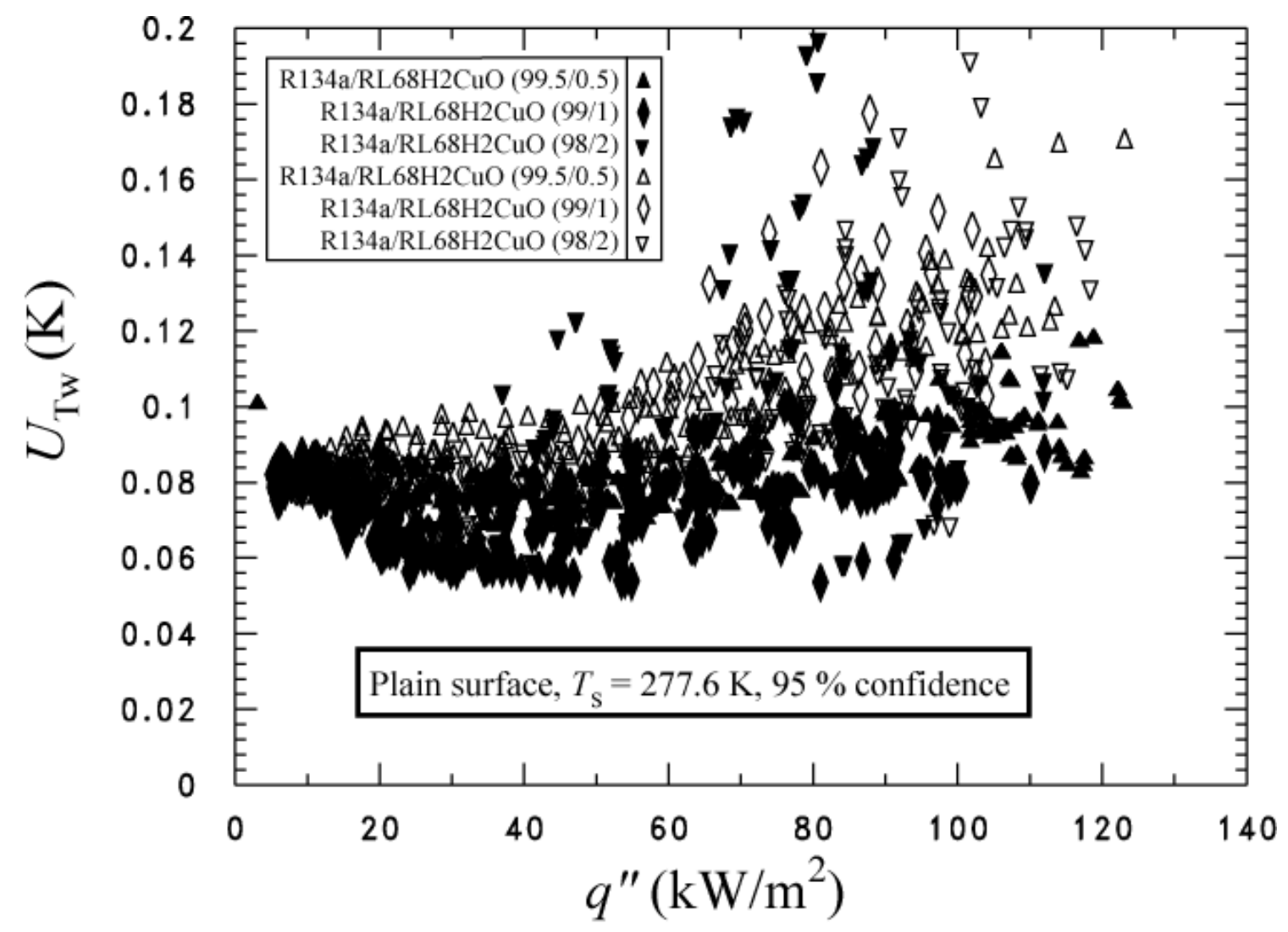

Fig. A.2 Expanded uncertainty in the temperature of the surface at the $95 \%$ confidence level 